\title{
Seismic Control of Tall Buildings Using Distributed Multiple Tuned Mass Dampers
}

\author{
Hamid Radmard Rahmani (D) and Carsten Könke \\ Institute of Structural Mechanics, Bauhaus-Universität Weimar, Marienstr. 15, D-99423 Weimar, Germany \\ Correspondence should be addressed to Hamid Radmard Rahmani; radmard.rahmani@gmail.com
}

Received 5 March 2019; Revised 16 July 2019; Accepted 29 July 2019; Published 19 September 2019

Guest Editor: Edén Bojórquez

Copyright (c) 2019 Hamid Radmard Rahmani and Carsten Könke. This is an open access article distributed under the Creative Commons Attribution License, which permits unrestricted use, distribution, and reproduction in any medium, provided the original work is properly cited.

\begin{abstract}
The vibration control of tall buildings during earthquake excitations is a challenging task because of their complex seismic behavior. This paper investigates the optimum placement and properties of the tuned mass dampers (TMDs) in tall buildings, which are employed to control the vibrations during earthquakes. An algorithm was developed to spend a limited mass either in a single TMD or in multiple TMDs and distribute it optimally over the height of the building. The nondominated sorting genetic algorithm II (NSGA-II) method was improved by adding multivariant genetic operators and utilized to simultaneously study the optimum design parameters of the TMDs and the optimum placement. The results showed that, under earthquake excitations with noticeable amplitude in higher modes, distributing TMDs over the height of the building is more effective in mitigating the vibrations compared to the use of a single TMD system. From the optimization, it was observed that the locations of the TMDs were related to the stories corresponding to the maximum modal displacements in the lower modes and the stories corresponding to the maximum modal displacements in the modes which were highly activated by the earthquake excitations. It was also noted that the frequency content of the earthquake has significant influence on the optimum location of the TMDs.
\end{abstract}

\section{Introduction}

Given the modern development plans of large cities, which are designed to answer the needs of their fast-growing population, it is anticipated that the buildings in such cities will become taller and more expensive [1]. As result, the area of investigating solutions to provide safety and serviceability of tall buildings in case of natural hazards such as strong winds and earthquakes has gained much attention in the last decade.

The current seismic design codes allow the structures to undergo inelastic deformations during strong earthquakes. Such structures would experience larger deformations but less seismic forces; otherwise, the structure should sustain much larger earthquake loads.

On the contrary, the deformations under wind and earthquake loads are limited because of stability and serviceability provisions. The resultant structures are stiff enough to withstand the wind loads, without forming noticeable deformations, while simultaneously being ductile enough to withstand strong earthquakes by adopting nonlinear behaviors.

However, particularly for controlling the vibrations in tall buildings, the code-based approaches do not necessarily lead to an applicable and affordable solution, as these structures need to withstand much larger wind and earthquake loads even though they have much lower lateral stiffness compared to low- and midrise buildings. Moreover, because of their very high construction costs, they are usually designed to endure for longer time periods, which increase their risk of experiencing strong earthquakes over the course of their service life.

A modern answer to these issues is the idea of structural control systems that include a variety of techniques, which can be classified into four main categories: passive, active, semiactive, and hybrid.

From a historical point of view, passive control systems such as base isolations and tuned mass dampers (TMDs) 
were the first of these techniques to be implemented. Considerable research has focused on the passive controller systems, and they are already utilized in many countries $[2,3]$. As these systems need no external power supply, they are easier to implement and design, when compared to other advanced controllers. In structural control problems, TMDs have been successfully implemented in different structures such as bridges $[4,5]$ and buildings $[6-11]$ to reduce earthquake- and wind-induced vibrations. Observations of TMDs show that they can effectively reduce vibrations in structures that are excited by high winds, high-speed trains, and traffic loads and also help decrease the discomfort of the inhabitants during minor earthquakes $[5,12,13]$. Under earthquake excitations, the literature shows that the performance of the TMDs decreases as the duration of excitation shortens. Therefore, the TMDs are more effective for structures subjected to narrowband long-duration far-fault (FF) excitations compared to pulse-like near-fault (NF) ground motions. As single TMD systems can be tuned to a particular frequency, they are very sensitive to mistuning and uncertainties. As a solution, multiple tuned mass dampers (MTMDs) were first introduced by Xu et al. in 1990 [14], after which they have been studied in several research studies $[8,9,11,15-19]$. $\mathrm{Li}$ and $\mathrm{Qu}[20]$ considered the structure as a single-degree-of-freedom (SDOF) system, when connected to multiple TMDs, and studied the optimum design parameters for those TMDs. With respect to using MTMD systems in multistory buildings, Chen and $\mathrm{Wu}$ [8] studied the efficiency of using multiple TMDs in mitigating the seismic responses in a six-story building. After that, Sakr [15] used partial floor loads as MTMDs. These research studies show that the MTMD systems cover a wider frequency range and are less sensitive to the uncertainties of the system.

In addition to multistory buildings, several tall buildings have benefited from the utilization of TMDs in controlling their vibrations (see Figure 1).

As has been shown, most of them are equipped with a single TMD, which is placed on the top level of the building. The studies also showed that using a single TMD on the top levels of the tall buildings can effectively reduce wind-induced motions $[22,23]$. This is because the structures respond to the wind excitation with respect to their first structural mode in which the top levels of the building have maximum modal displacement. Therefore, placing a single TMD on the top level with a tuning frequency closer to the fundamental structural frequency can efficiently reduce the structural responses. In another research, Elias and Matsagar [9] studied the use of distributed MTMD systems in reducing wind-induced vibrations in a tall building. They concluded that the distributed MTMDs are more effective, as compared to a single TMD system and an MTMD system in which all the TMDs are placed on the top level.

The research studies show that TMDs are also effective in mitigating earthquake vibrations in buildings. Arfiadi and Hadi [6] used a hybrid genetic algorithm method to find the optimum properties and the location of a TMD for a 10story building under earthquake excitation. In another research, Pourzeinali et al. [24] utilized multiobjective optimization to outline the design parameters of a TMD in a 12-story building under earthquake excitation. Li [11] proposed a novel optimum criterion to optimize the properties of double TMDs for structures under ground acceleration. In another research, Elias et al. studied the effectiveness of a distributed TMD system in vibration control of a chimney [25]. The research developments in passive control of structures using TMDs are summarized by Elias and Matsagar [26].

In all the research studies about tall buildings cited here, either the parameters of the TMDs have mainly been studied under wind-induced vibrations or a single TMD has been studied under earthquake excitation; currently, studying the optimum parameters of TMDs under earthquake excitation, without limiting the number and location of TMDs, is still a challenging task because of the stochastic nature of the earthquakes and the complex seismic behavior of such buildings, which mandate extensive and thorough studies.

Additionally, in contrast to the wind loads, during earthquakes, the higher modes may have more noticeable participation in the total response of tall buildings. This is mainly because of the (1) low frequency of the higher modes in these structures, compared to low- and midrise buildings, and (2) wide frequency content of the earthquakes that may activate multiple modes in such buildings. Therefore, only controlling the lower modes by placing TMDs on the top levels would not necessarily lead to the optimum solution for controlling the motions in these buildings during earthquakes.

1.1. Problem Definition. This paper addresses the mentioned issues by studying the optimum placement and properties of TMDs in a 76-story benchmark building as the case study which is subjected to seven scaled earthquake excitations. The variables of the resultant optimization problem include the positions and properties of the TMD. The goal of the optimization is to reduce the controlled-to-uncontrolled ratio of the displacement, velocity, and acceleration seismic responses. In order to solve such multiobjective optimization problem, an improved revision of the nondominated sorting genetic algorithm II (NSGA-II) is developed and utilized.

In each loop, the algorithm generates an arrangement and properties of the TMDs using the NSGA-II method and sends them to the analyzer module to determine the responses of the building equipped with such a TMD arrangement under different earthquake excitations. Based on the responses, the algorithm assigns a fitness value for such TMD arrangements. The fitness value is an index that shows how good or bad the obtained responses are. The NSGA-II then utilizes a refined history of the TMD arrangements and corresponding fitness values for its next suggestion in the next loop. In this study, the algorithm was allowed to spend an applicable mass in a single TMD or distribute it through multiple TMDs over the height of the building.

1.2. Contributions. This research incorporates several contributions in the field of passive control of tall buildings and 


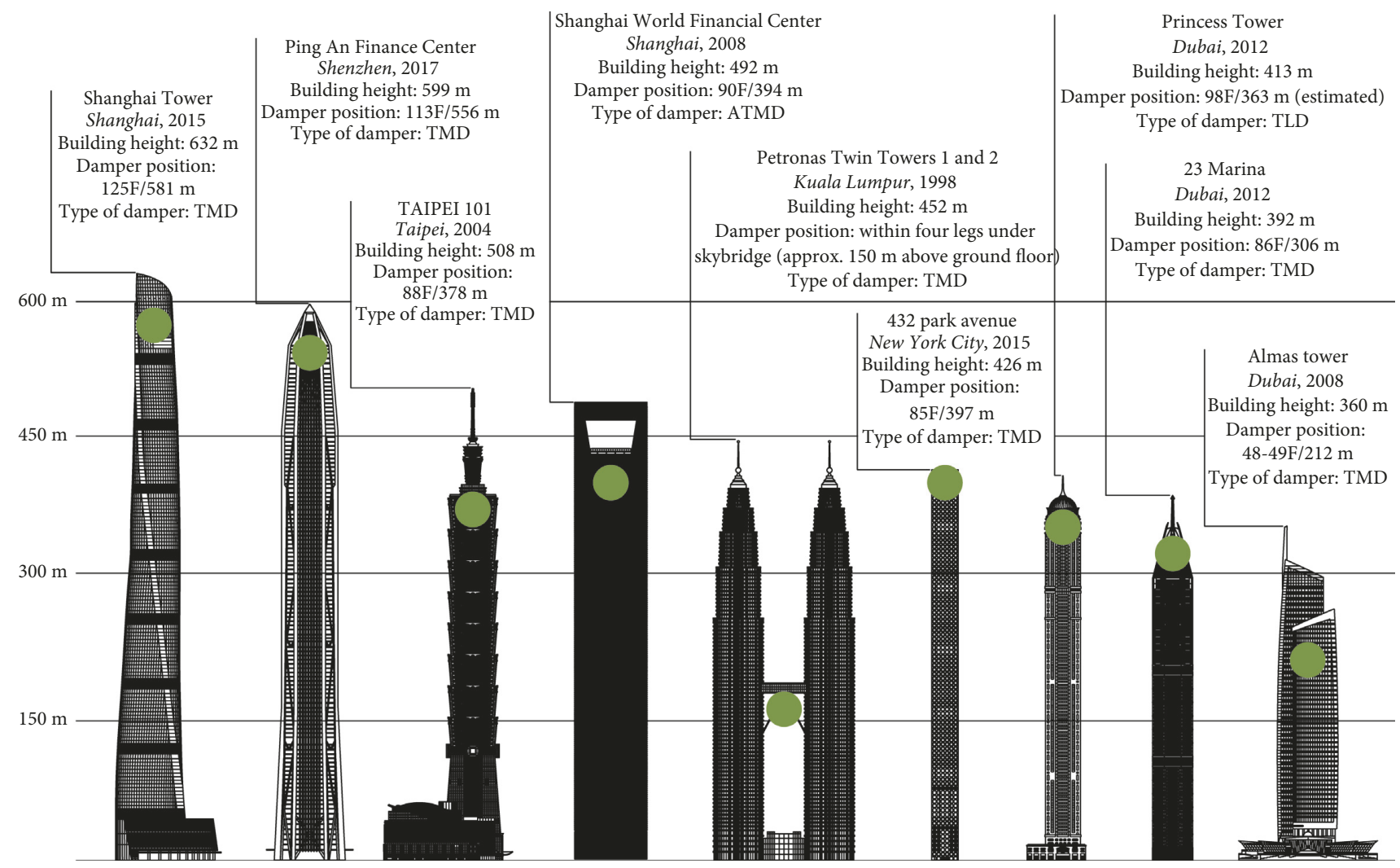

Figure 1: Tallest completed buildings with dampers [21].

optimization problems. First, the issues with a single TMD system in controlling tall buildings are addressed, and improvements are proposed by studying multimode control via distribution of the TMDs over the height of the building. Likewise, it investigates how the frequency content of the earthquake can affect the optimum position and properties of the TMDs. Moreover, the performance of the NSGA-II algorithm is enhanced by adding multivariant genetic operations, and the resulting algorithms are presented. Finally, the optimum hyperparameters of the genetic algorithm for tackling similar problems are proposed by performing sensitivity analysis.

1.3. Outlines. The mathematical settings of a structural dynamic problem are mentioned in Section 2. Then, the NSGA-II method is described in Section 3. After that, the case study is presented in Section 4, and the selection and scaling of the earthquakes are noted. Then, the results of the sensitivity analysis of the GA hyperparameters for optimizing the performance of the GA algorithm are presented, and the optimization process is then detailed in Section 7. Finally, the obtained results are presented and discussed in Sections 8 and 9, and the relevant conclusions are drawn.

\section{Mathematical Model of the Building}

The governing equation of the motion of a tall building under earthquake excitation is as follows:

$$
[M]\{\ddot{U}\}+[C]\{\dot{U}\}+[K]\{U\}=\left\{P_{\mathrm{t}}\right\},
$$

where $M, K$, and $C$ represent the mass, the stiffness, and the damping matrices of the structure and the TMDs:

$$
\begin{aligned}
{[M] } & =\left[M_{s t}\right]+\left[M_{t}\right], \\
{[C] } & =\left[C_{s t}\right]+\left[C_{t}\right], \\
{[K] } & =\left[K_{s t}\right]+\left[K_{t}\right] .
\end{aligned}
$$

Indexes st and $t$ indicate the degree of freedom (DOF) of the building and the TMDs, respectively.

The external load vector, $P_{t}$, in Equation (1) comprises inertial forces due to ground accelerations as follows:

$$
\left\{P_{\mathrm{t}}\right\}=-\ddot{u}_{\mathrm{g}}[M]\left\{1_{\mathrm{t}}\right\},
$$

where $\left\{1_{t}\right\}_{(N+n) \times 1}=[1,1, \ldots, 1]^{T}$ and the term $\ddot{u}_{\mathrm{g}}$ represents the ground accelerations.

The structural responses, including displacement, velocity, and acceleration matrices, can be expressed as follows:

$$
\begin{aligned}
& \{U\}=\left\{u_{s t 1}, u_{s t 2}, \ldots, u_{s t N}, u_{t 1}, u_{t 2}, \ldots, u_{t n}\right\}, \\
& \{V\}=\left\{v_{s t 1}, v_{s t 2}, \ldots, v_{s t N}, v_{t 1}, v_{t 2}, \ldots, v_{t n}\right\}, \\
& \{A\}=\left\{a_{s t 1}, a_{s t 2}, \ldots, a_{s t N}, a_{t 1}, a_{t 2}, \ldots, a_{t n}\right\},
\end{aligned}
$$

where $N$ and $n$ represent the number of DOFs (DOF) for the building and the TMDs, respectively. Therefore, the dimensions of the $M, K$, and $C$ matrices are $(N+n) \times(N+n)$. 
The design parameters of a TMD include its damping, tuning frequency, and mass. Generally, the ratios of these parameters to the corresponding values of the structures have more importance and are utilized in the design procedures:

$$
\begin{aligned}
m_{0} & =\frac{m_{t}}{m_{s t}}, \\
\beta & =\frac{v_{t}}{v_{s t}}, \\
\psi & =\frac{c_{t}}{c_{s t}},
\end{aligned}
$$

where the parameters $m_{0}, \beta$, and $\psi$ refer to mass, frequency, and damping ratios, while the indexes $t$ and st indicate the TMD and the structural properties.

In order to solve the equations of the motion, Newmark's $\beta$ method is utilized. The average acceleration method is considered by setting $\gamma=1 / 2$ and $\beta=1 / 4$ in the related formulations [27].

\section{The Fast and Elitist Multiobjective Genetic Algorithm NSGA-II}

3.1. Introduction. In this paper, the NSGA-II method [28] is utilized to investigate the optimum arrangement and properties of TMDs in a tall building. NSGA-II is a nondomination-based genetic algorithm invented for multiobjective optimization problems. In this method, the initial population is randomly generated, as in a normal GA procedure, and then the algorithm sorts the population with respect to the nondomination rank and the crowding distance.

In general, $X$ dominates $Y$ if $X$ is no worse than $Y$ in all the objectives and if $X$ is better than $Y$ in at least one objective.

Among the nondominated solutions or a union of the first ranks of nondominated solutions, NSGA-II seeks a broad coverage. This will be achieved by crowding distance, which is the Manhattan distance between the left and right neighboring solutions for two objectives.

3.2. Repair. The repair method makes infeasible solutions feasible. Figure 2 schematically shows the repair approach for a solution space with an infeasible solution and two solutions in the feasible region. In this research, an infeasible solution includes the out-of-limit properties for TMDs. As is shown, the repair function would project each of these infeasible solutions to the closest feasible solution. The developed repair function calculates the shortest distance of the TMD properties $\left(m_{0}, \beta\right.$, and $\left.\psi\right)$ in the infeasible solution and corrects the chromosome with respect to the calculated distance (see Algorithm 1).

3.3. Selection. The objective of selection is to choose the fitter individuals in the population to create offsprings for the next generation and then place them in a group commonly

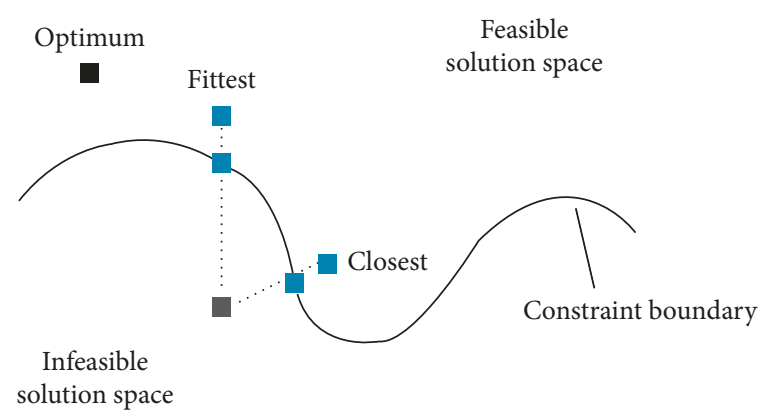

Figure 2: Repair of an infeasible solution [29].

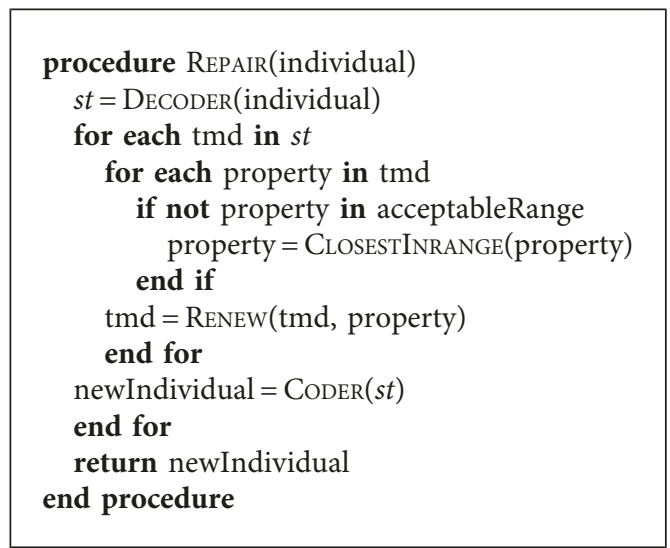

Algorithm 1: Repairing individuals.

known as the mating pool. The mating pool is then subjected to further genetic operations that result in advancing the population to the next generation and hopefully closer to the optimal solution. In this research, the roulette wheel selection method was utilized for developing the selector function. As is also shown in Algorithm 2, the algorithm selects the individuals based on a probability proportional to the fitness. As is schematically illustrated in Figure 3, the principle of roulette selection is a linear search through a roulette wheel with the slots in the wheel weighted in proportion to the individual's fitness values. All the chromosomes (individuals) in the population are placed on the roulette wheel according to their fitness value [30]. In this algorithm, a probability value is assigned to each individual in the population. Based on these probabilities, the ranges $[0$, 1] are divided between the individuals so that each individual obtains a unique range. The winning individual is then selected by generating a random number between zero and one and finding the individual whose range includes this random number.

In this algorithm, the ADDRANGE function assigns a range to each individual based on their fitness value and their position on the wheel and the $R N D(1)$ function generates a random value between zero and one.

3.4. Optimization Variables. In this study, three variables were defined to be optimized by the NSGA. As is schematically shown in Figure 4, the variables are as follows: 


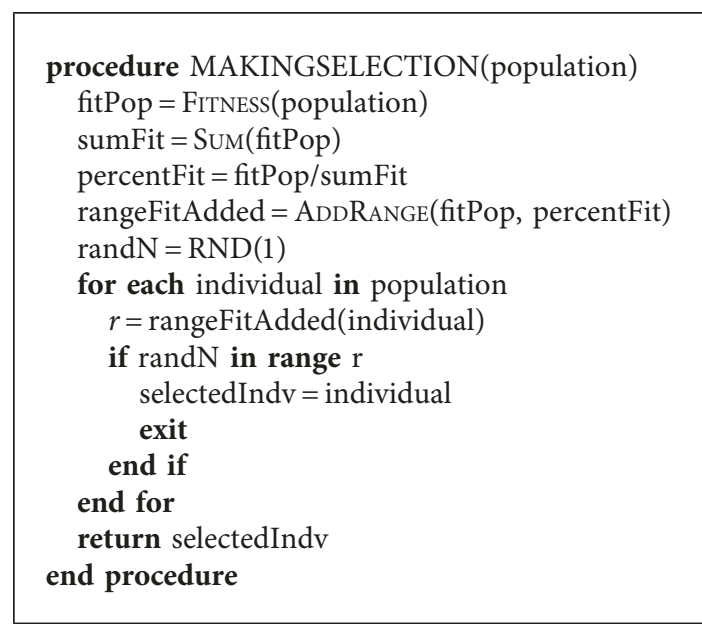

Algorithm 2: Making individual selection.

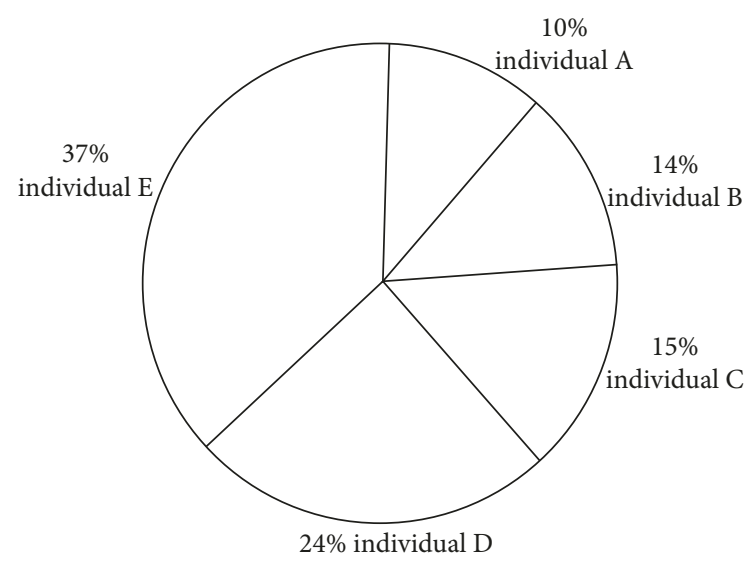

FIGURE 3: Roulette wheel selection.

(1) Number of TMDs

(2) Position of the TMDs $\longrightarrow$ story number

(3) TMDs' properties $\longrightarrow m_{0}, \beta$, and $\psi$

The variation domain for $m_{0}, \beta$, and $\psi$ is considered to be in an applicable range, as shown in Table 1. The maximum value of the total mass ratio of TMDs, $m_{\mathrm{t}}=\sum_{i=1}^{n} m_{0 i}$, is limited to $3 \%$, which is equal to the considered limit for each TMD. This allows the GA algorithm to either spend the allowable mass in a single TMD or divide it among multiple TMDs and distribute them over the height of the building. As is shown, the damping and the frequency ratio of the TMDs are also limited to applicable values.

3.5. Encoding. In this research, binary coding has been considered for creating genes. Therefore, the design variables of each TMD are coded into a binary string with a constant number of genes as shown in Figure 5. Each offspring contains the design parameters for the TMD as follows:
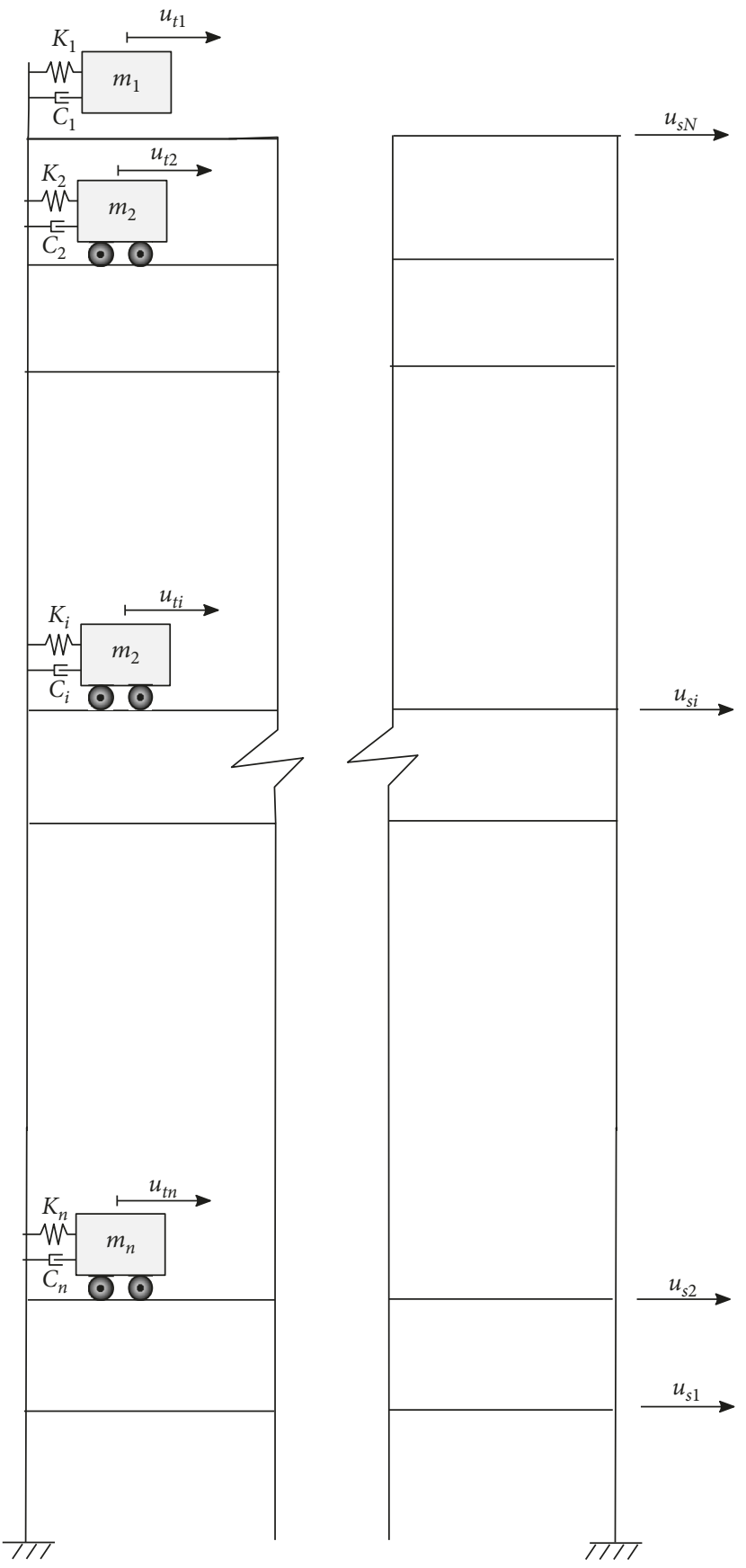

FIgURE 4: Building equipped with TMDs.

$$
\begin{aligned}
m_{0} & =\frac{m_{t}}{m_{s t}}, \\
\beta & =\frac{v_{t}}{v_{s t}}, \\
\xi & =\frac{c_{t}}{c_{s t}},
\end{aligned}
$$

where the $t$ and $s t$ indexes correspond to the TMD and the structure, respectively. 
TABle 1: Parameter variation domain for TMDs.

\begin{tabular}{lcc}
\hline Parameters & Min. value & Max. value \\
\hline$m_{\mathrm{t}}(\%)$ & - & 3 \\
$m_{0}(\%)$ & 0.2 & 3 \\
$\beta$ & 0.8 & 1.3 \\
$\psi$ & 5 & 40 \\
\hline
\end{tabular}

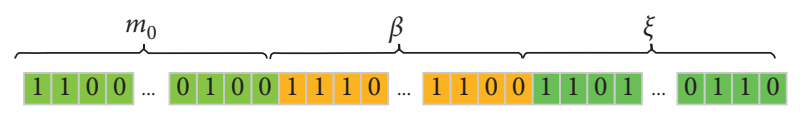

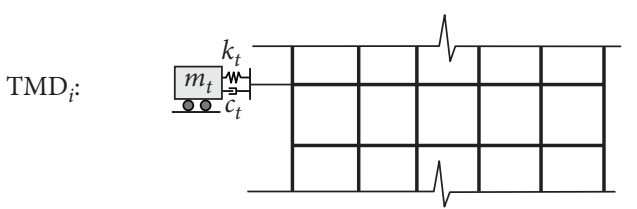

FIGURE 5: Binary coding the TMD's properties.

After developing the genes for each TMD, the chromosomes are then created by combining all genes for each solution. As a result, each chromosome contains the coded data of all TMDs in the building. Using this definition, the position of each TMD is represented by the position of the related genes in the chromosome.

\subsection{Genetic Operators}

3.6.1. Crossover Function. In the crossover operation, two selected parents exchange random parts of their chromosome to create new offsprings. An appropriate strategy for selecting locations of the split points and the length of the transferred genes depends on the problem characteristics that highly affect the performance of the algorithm and the quality of the final results.

In this regard, different alternatives have been studied in this research to develop an appropriate crossover function. Examples of crossover operation forms that have been utilized in other research studies but were not appropriate for this research are discussed as follows:

(1) Single/k-Point Crossover: Random Points in Whole Chromosome. In the initial steps, a completely random selection of the genes for crossover has been considered as a commonly used crossover function. In this crossover type, after the parents are nominated by the algorithm, one or $k$ points in the chromosome are randomly selected, and the new offsprings are created by splitting and combining the parents' chromosomes at the selected points. This process has often resulted in producing too many meaningless and low-quality offsprings, consequently reducing the performance of the algorithm dramatically. Examples of meaningless offsprings can include TMDs without one or more properties (e.g., without mass or stiffness).

(2) Single/k-Point Crossover: Random Points in TMD Genes. Preventing the production of meaningless offsprings, the crossover function was improved in this study so that the genes related to the TMDs in each parent could be selected for performing a k-point crossover. Although the chance of creating meaningless offsprings was noticeably reduced, the results showed that the efficiency of the operator in improving the results was not acceptable, as following this process, all the genes within the considered range for a TMD would be subjected to the same operations regardless of the genes' positions.

For example, the genes related to the stiffness of a TMD in a parent were exchanged with those related to the damping properties in another parent, which is not logical. As a result, despite its improvements compared to the first type, the second crossover type leads to a very low convergence rate because of the production of low-quality offsprings. In addition, one possible shortcut for reaching an optimum solution was missed; this step involves attaching the TMD of one parent to a story in another parent.

However, the maximum convergence rate obtained by developing a two-variant crossover function is presented in Algorithm 3. As is shown, in this function, in each call, one of the two developed crossover variants would be selected randomly. These variants are described as follows:

(i) Variant 1: in the first variation, the crossover operator acts on each of the parameters of the TMDs separately using the k-point crossover method, meaning that, in each call, the crossover operator acts on the stiffness, mass, or damping of the parents and exchanges the related properties using the $\mathrm{k}$-point crossover function. The produced offsprings have TMDs in the same locations as their parents, but with different properties. Investigation of the performance of this function showed that this variant improves the parameters of the TMDs regardless of their positions.

(ii) Variant 2: the second crossover variation acts on the location of TMDs in the parents. The resultant offsprings include TMDs with the same properties as their parents but in other stories. These two crossover variations are demonstrated in Figure 6.

3.6.2. Mutation Function. In the genetic algorithm, the mutation operator randomly changes one or multiple genes of a parent to produce new offsprings. Generally, in the binary coded chromosome, the following function is utilized to change the genes:

$$
\text { Binary mutation }(\text { gen })= \begin{cases}1, & \text { if gen value }=0, \\ 0, & \text { if gen value }=1 .\end{cases}
$$

In GA problems, the mutation function helps the algorithm to explore the solution space more broadly and prevents it from sticking to the local minimums. In addition, a proper mutation function improves the convergence speed. In this research, in order to develop an appropriate mutation function, different variants were studied. It is understood that developing the mutation function without considering the characteristics of the problem would result in producing meaningless 


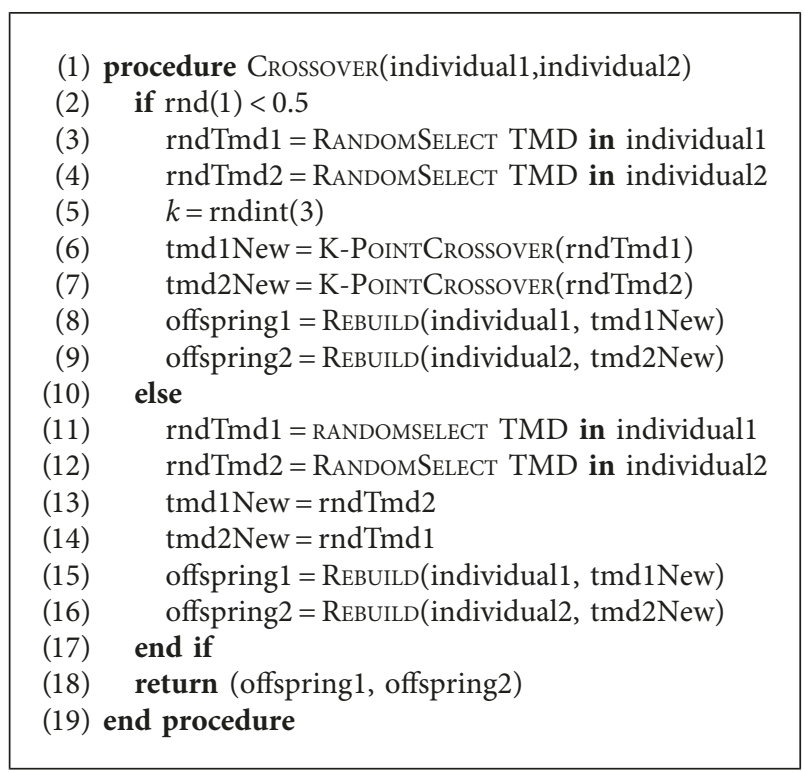

Algorithm 3: Crossover operator.

offsprings. Keeping this in mind, a two-variant mutation function was developed, which acted on the (1) genes related to TMD parameters and (2) group of genes related to the location of the TMDs (See Algorithm 4).

3.7. Fitness Function. During the GA procedure, each solution comprised an arrangement of TMDs with different parameters. In order to evaluate an individual solution, three objective functions were defined to shape the fitness function. The objectives of the optimization were taken to be the maximum ratios of displacement, velocity, and acceleration responses in controlled condition to their uncontrolled values as follows:

$$
\begin{aligned}
& J_{1}=\max \cdot\left(\frac{u_{i}^{C}}{u_{i}^{U C}}\right)_{i=1, \ldots, N}, \\
& J_{2}=\max \cdot\left(\frac{v_{i}^{C}}{v_{i}^{U C}}\right)_{i=1, \ldots, N}, \\
& J_{3}=\max \cdot\left(\frac{a_{i}^{C}}{a_{i}^{U C}}\right)_{i=1, \ldots, N},
\end{aligned}
$$

where $i$ is the story number and $N$ is the number of stories in the building. The pseudocode of the developed fitness function is presented in Algorithm 5.

\section{Benchmark Building}

As a case study, a 76-story, $306 \mathrm{~m}$ tall official building consisting of the concrete core and concrete frames was considered. The total mass of the building was 153,000 tonnes. The initial mathematical model of the building included 76 transitional and 76 rotational degrees of freedom in which the rotational degrees of freedom were then removed by the static condensation method to create a 76- degree-of-freedom model. The damping matrix of the building was calculated by considering a $1 \%$ damping ratio for the first five modes using Rayleigh's approach.

The first five natural frequencies of the building were $0.16,0.765,1.992,3.79$, and $6.39 \mathrm{~Hz}$. The first five mode shapes of the building are presented in Figure 7.

\section{Ground Motion Selection}

In this research, the ground motions were selected and scaled using an intensity-based assessment procedure, considered according to ASCE/SEI 07-10. In this regard, seven earthquakes' real acceleration records were selected from the Pacific Earthquake Engineering Research Center (PEER) NGA strong motion database [31] (see Figure 8) and then scaled using a design response spectrum $[32,33]$. The peak ground acceleration (PGA) and other seismic parameters of the considered design response spectrum are shown in Table 2.

The specifications of the nonscaled and scaled selected earthquakes are presented in Tables 3 and 4 . The spectra of the nonscaled and scaled excitations are shown in Figure 9.

\section{Sensitivity Analysis of Genetic Algorithm Parameters}

As the parameters of GAs are highly dependent on the characteristics of each particular problem [34], the sensitivity analysis on the GA parameters was performed and the optimum values were studied. Utilization of the obtained values for the GA parameters resulted in improving the quality of the solutions and the performance of the algorithm. As is shown in Table 5, during the sensitivity analysis, the crossover and mutation probabilities were iterated, and the GA results were compared for the El Centro earthquake excitation.

The results were then sorted using the NSGA function, and the pareto fronts were obtained, as shown in Table 6 . Considering the first pareto set in this table, the resultant optimum values for crossover and mutation probabilities were 0.7 and 0.2 , respectively.

As a result, the parameters of the NSGA-II were considered as they are shown in Table 7. The sufficiency of 500 generations as the limit for the number of generations was then evaluated, as shown in Figure 10.

\section{Optimization Process}

In order to study the optimum arrangement and properties of the TMD in the benchmark building, a computer code was developed based on the previously discussed theories and functions. The pseudocode of the program is presented in Algorithm 6. In order to improve the performance of the developed code and reduce the computation time, some advanced computer programming techniques, such as parallel computing, were utilized. As a result, the code utilized multiple CPU cores to produce multiple populations in parallel, and then all the populations were combined and sorted in each generation. 


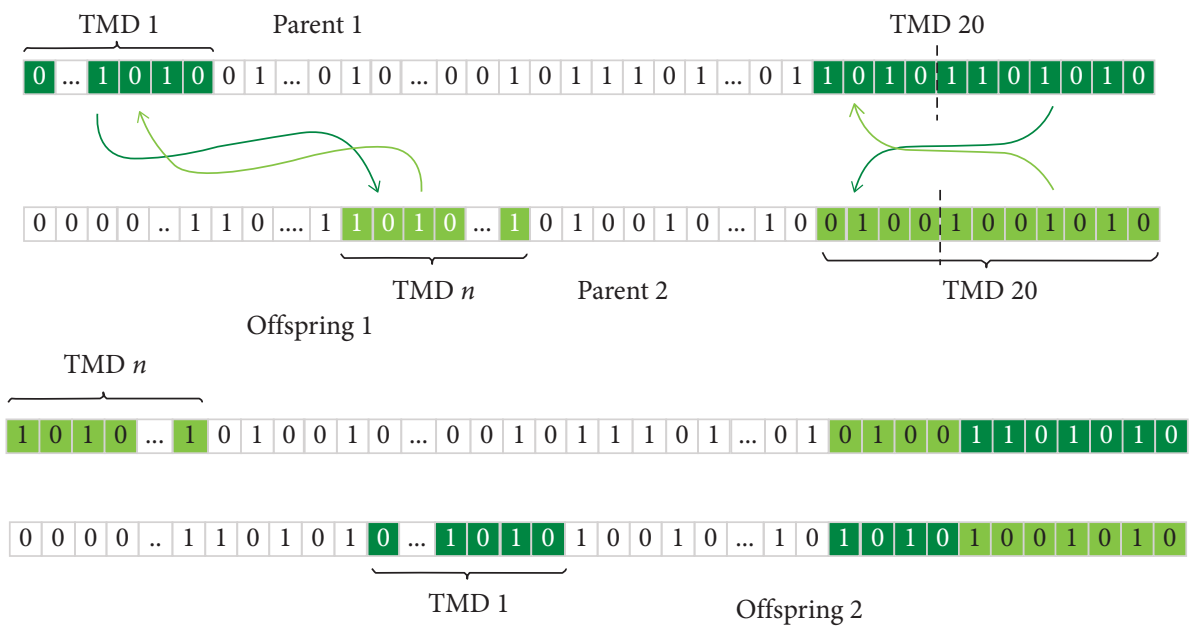

Figure 6: Crossover types.

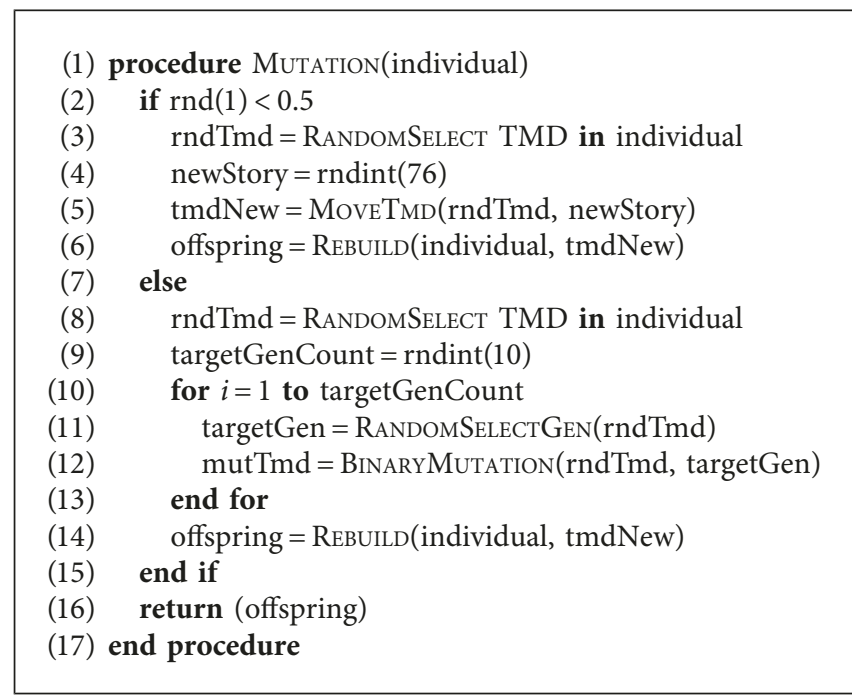

Algorithm 4: Mutation operator.

(1) procedure FITNEss(benchmarkData, individualTmdAdded, excitation)

(2) $\left\{u_{\max }^{\text {controlled }}, v_{\max }^{\text {controlled }}, a_{\max }^{\text {controlled }}\right\}=$ MAXRESPONSE(benchmarkData, individualTmdAdded, excitation)

(3) type $\left\{u_{\max }^{\text {uncontrolled }}, v_{\max }^{\text {uncontrolled }}, a_{\max }^{\text {uncontrolled }}\right\}$ as constant

(4) $j_{1}=u_{\max }^{\text {controlled }} \backslash u_{\text {max }}^{\text {uncontrolled }}$

$j_{1}=u_{\max }^{\operatorname{cox}}$
(5) $j_{2}=v^{\text {controlled }} \backslash v_{\max }^{\text {uncontrolled }}$

(6) $j_{3}=a_{\max }^{\text {controlled }} \backslash a_{\max }^{\text {uncontrolled }}$

(7) indvFitnessAdded $=$ [individualTmdAdded, $\left\{j_{1}, j_{2}, j_{3}\right\}$ ]

(8) return (indvFitnessAdded)

(9) end procedure

Algorithm 5: Fitness of individuals.

\section{Results}

The results of the optimization process, including the optimum arrangement of the TMDs and their properties, are shown in Figures 11-17. The drift and acceleration responses for the top story, as the critical story, are summarized in Table 8. As shown, the optimum number of TMDs is more than one for some of the excitations.

The maximum number of TMDs is three, which corresponds to Bam and Manjil excitations, placed in 76, 75, 

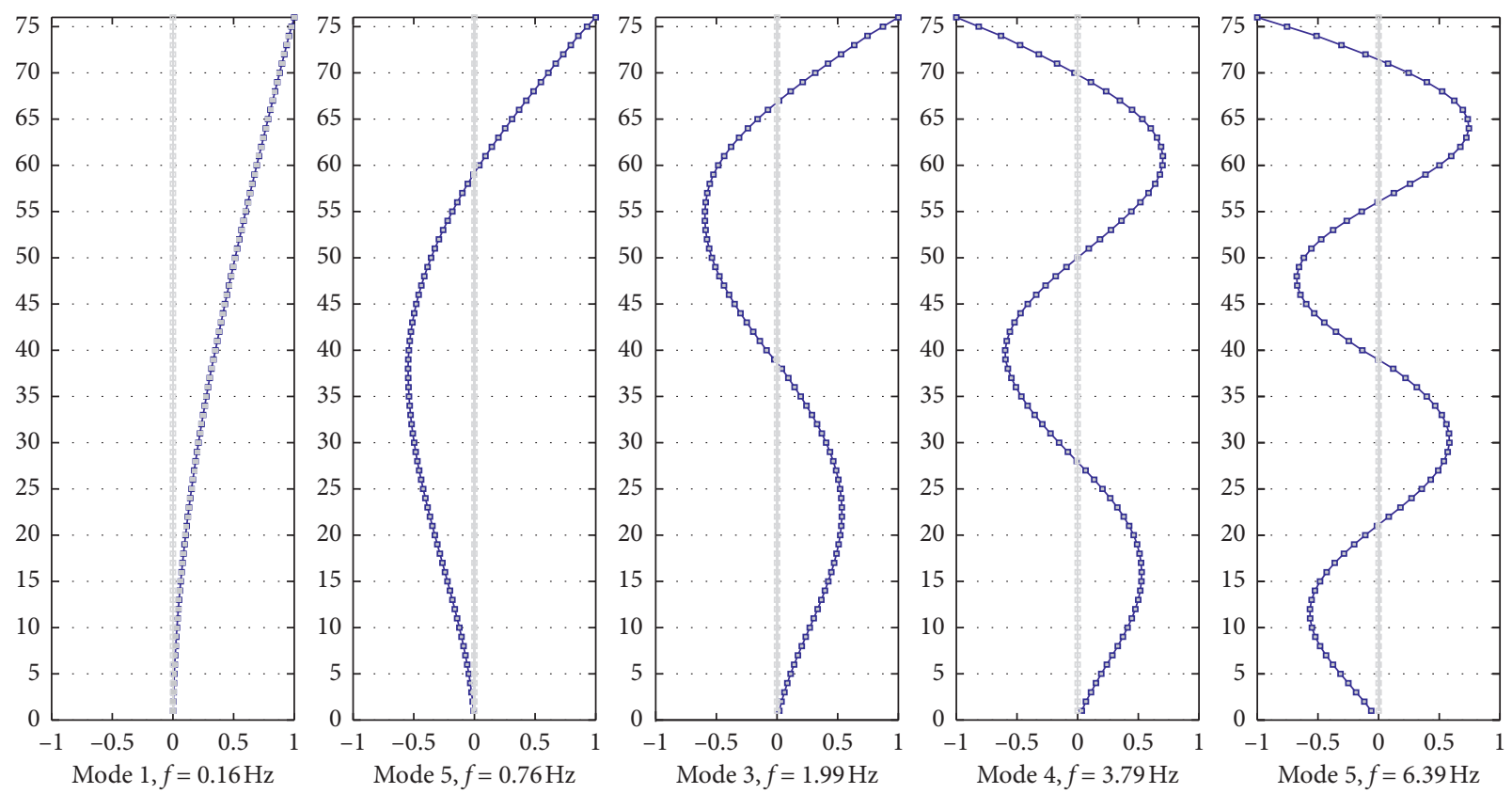

Figure 7: Five mode shapes of the 76-story building.

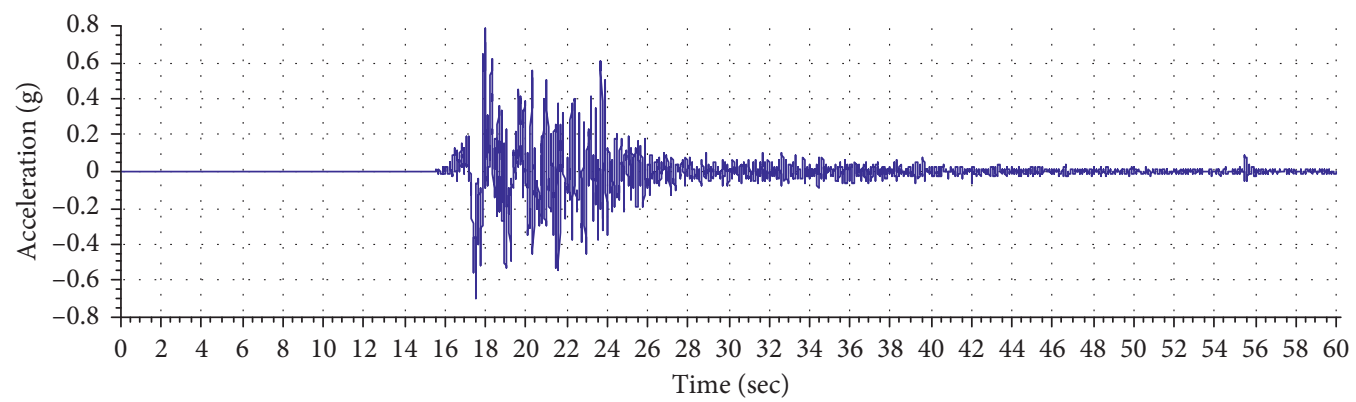

(a)

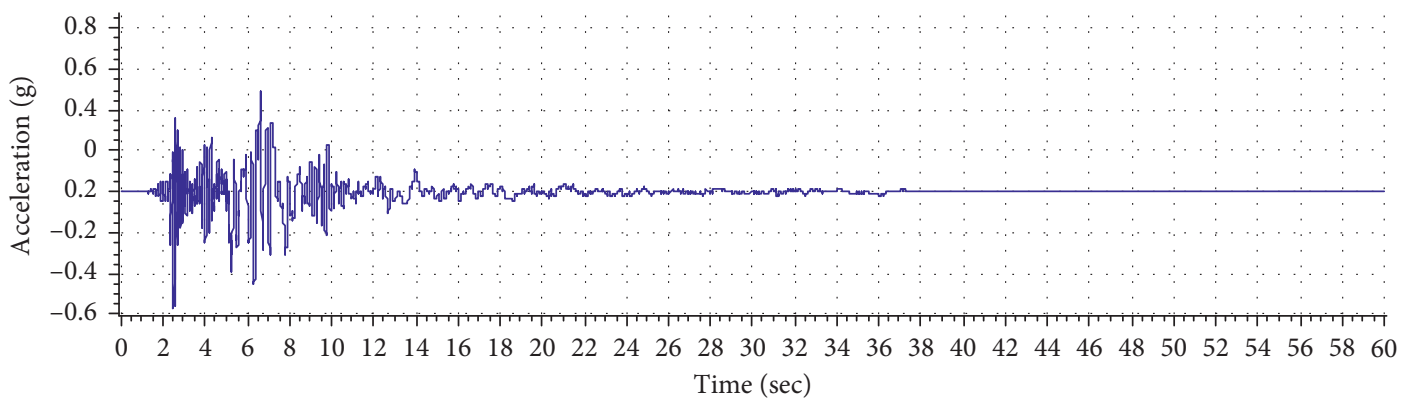

(b)

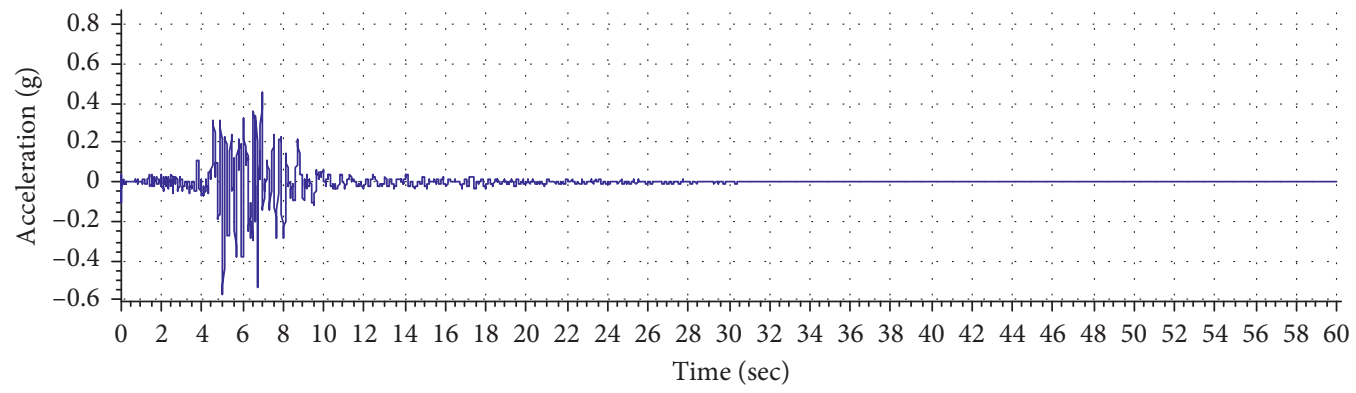

(c)

FIGURE 8: Continued. 


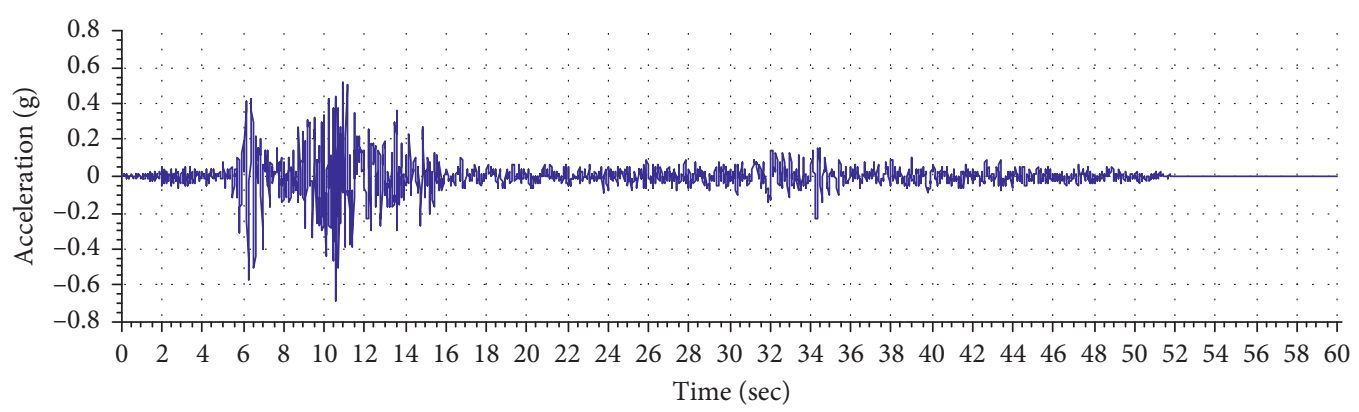

(d)

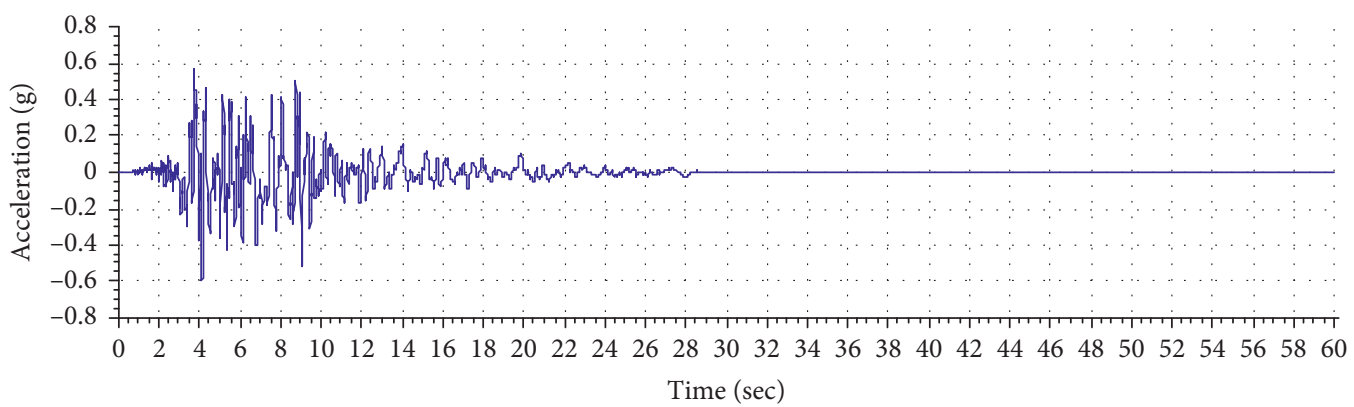

(e)

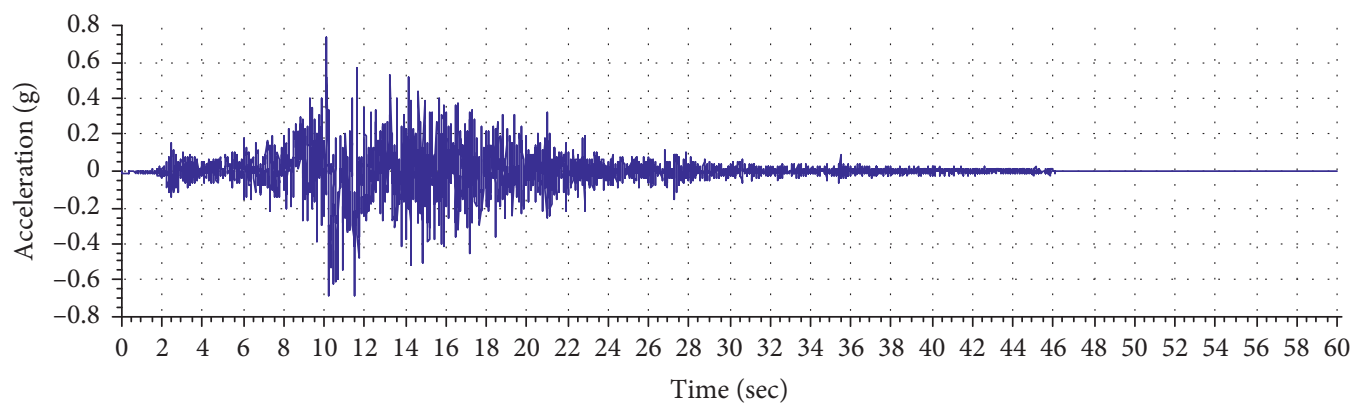

(f)

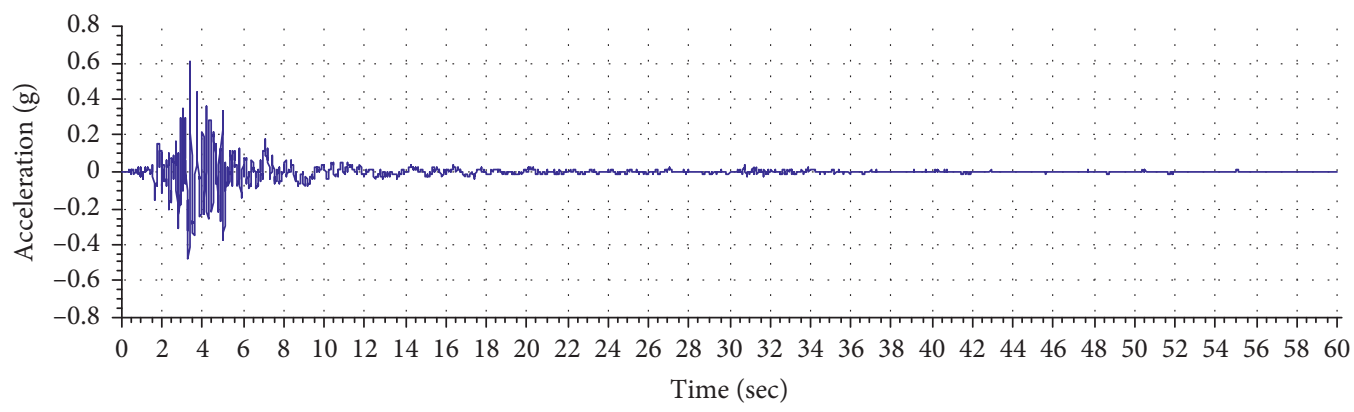

(g)

FIGURE 8: Earthquake acceleration records obtained from Pacific Earthquake Engineering Research Center (PEER) [31]. (a) Bam, Iran, 2003. (b) El Centro, USA, 1940. (c) Kobe, Japan, 1995. (d) Manjil, Iran, 2002. (e) Northridge, USA, 1971. (f) Landers, USA, 1992. (g) San Fernando, USA, 1994.

Table 2: Parameters of the design response spectrum.

\begin{tabular}{lccccccccc}
\hline Site class & PGA & $S_{s}$ & $S_{1}$ & $F_{a}$ & $F_{v}$ & $S_{\mathrm{MS}}$ & $S_{M 1}$ & $S_{\mathrm{DS}}$ & $S_{D 1}$ \\
\hline $\mathrm{B}$ & 0.919 & $2.431 \mathrm{~g}$ & $0.852 \mathrm{~g}$ & 1 & 1 & $2.431 \mathrm{~g}$ & $0.852 \mathrm{~g}$ & $1.621 \mathrm{~g}$ & $0.568 \mathrm{~g}$ \\
\hline
\end{tabular}


TABLE 3: Original earthquakes' specifications.

\begin{tabular}{lcccccc}
\hline Accelerogram & Max. acceleration $(\mathrm{g})$ & $\begin{array}{c}\text { Max. velocity } \\
(\mathrm{cm} / \mathrm{sec})\end{array}$ & Max. displacement $(\mathrm{cm})$ & $\begin{array}{c}\text { Effective design } \\
\text { acceleration }(\mathrm{g})\end{array}$ & $\begin{array}{c}\text { Predominant } \\
\text { period }(\mathrm{sec})\end{array}$ & $\begin{array}{c}\text { Significant } \\
\text { duration }(\mathrm{sec})\end{array}$ \\
\hline Bam & 0.80 & 124.12 & 33.94 & 0.69 & 0.20 & 8.00 \\
El Centro & 0.44 & 67.01 & 27.89 & 0.30 & 0.06 \\
Kobe & 0.31 & 30.80 & 7.47 & 0.28 & 0.42 & 11.46 \\
Manjil & 0.51 & 42.45 & 14.87 & 0.47 & 0.16 & 28.20 \\
Northridge & 0.45 & 60.14 & 21.89 & 0.45 & 0.42 \\
Landers & 0.72 & 133.40 & 113.92 & 0.52 & 0.08 \\
San Fernando & 0.22 & 21.71 & 15.91 & 0.20 & 0.00 & 13.62 \\
\hline
\end{tabular}

TABLE 4: Scaled earthquakes' specifications.

Accelerogram Max. acceleration (g) Max. velocity $(\mathrm{cm} / \mathrm{sec})$ Max. displacement $(\mathrm{cm})$ Effective design Predominant Significant

\begin{tabular}{lcccccc} 
& & & & acceleration $(\mathrm{g})$ & period $(\mathrm{sec})$ & duration $(\mathrm{sec})$ \\
\hline Bam & 0.78 & 128.55 & 33.95 & 0.64 & 0.20 & 8.24 \\
El Centro & 0.57 & 75.76 & 28.36 & 0.48 & 0.32 & 9.16 \\
Kobe & 0.56 & 38.83 & 15.68 & 0.56 & 0.36 & 4.16 \\
Manjil & 0.68 & 42.06 & 15.02 & 0.55 & 0.08 & 28.26 \\
Northridge & 0.59 & 64.57 & 22.16 & 0.58 & 0.40 & 10.40 \\
Landers & 0.73 & 141.02 & 113.78 & 0.56 & 0.08 & 12.92 \\
San Fernando & 0.60 & 23.71 & 15.88 & 0.61 & 0.10 & 6.03 \\
\hline
\end{tabular}

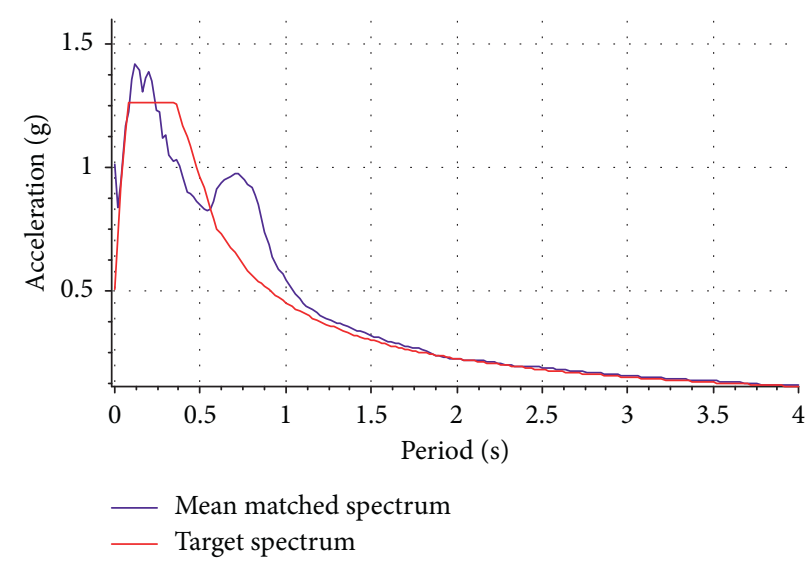

FIgURE 9: Mean matched spectrum compared to the target spectrum.

TABLE 5: Crossover and mutation variations.

\begin{tabular}{|c|c|c|c|c|c|}
\hline Variation no. & Crossover & Mutation & $J_{1}$ & $J_{2}$ & $J_{3}$ \\
\hline 1 & \multirow{4}{*}{0.6} & 0.1 & 0.845 & 0.917 & 0.941 \\
\hline 2 & & 0.2 & 0.860 & 0.926 & 0.950 \\
\hline 3 & & 0.3 & 0.855 & 0.924 & 0.948 \\
\hline 4 & & 0.4 & 0.839 & 0.915 & 0.942 \\
\hline 5 & \multirow{4}{*}{0.7} & 0.1 & 0.862 & 0.925 & 0.946 \\
\hline 6 & & 0.2 & 0.835 & 0.913 & 0.939 \\
\hline 7 & & 0.3 & 0.861 & 0.925 & 0.947 \\
\hline 8 & & 0.4 & 0.846 & 0.919 & 0.944 \\
\hline 9 & \multirow{4}{*}{0.8} & 0.1 & 0.869 & 0.929 & 0.950 \\
\hline 10 & & 0.2 & 0.876 & 0.932 & 0.952 \\
\hline 11 & & 0.3 & 0.842 & 0.915 & 0.941 \\
\hline 12 & & 0.4 & 0.852 & 0.922 & 0.947 \\
\hline 13 & \multirow{4}{*}{0.9} & 0.1 & 0.871 & 0.930 & 0.951 \\
\hline 14 & & 0.2 & 0.866 & 0.927 & 0.947 \\
\hline 15 & & 0.3 & 0.874 & 0.932 & 0.953 \\
\hline 16 & & 0.4 & 0.839 & 0.913 & 0.939 \\
\hline
\end{tabular}


TABLE 6: NSGA of crossover and mutation variations.

\begin{tabular}{lcc}
\hline Pareto front & Crossover variation no. & Mutation variation no. \\
\hline $\mathbf{1}$ & $\mathbf{6}$ & - \\
2 & 16 & - \\
3 & 4 & 11 \\
4 & 1 & - \\
5 & 8 & - \\
6 & 5 & 12 \\
7 & 3 & 7 \\
8 & 2 & 14 \\
9 & 9 & - \\
10 & 13 & - \\
11 & 10 & 15 \\
\hline
\end{tabular}

TABLE 7: Initial parameters of NSGA-II.

\begin{tabular}{lccc}
\hline $\begin{array}{l}\text { Number of } \\
\text { generations }\end{array}$ & $\begin{array}{c}\text { Population } \\
\text { size }\end{array}$ & $\begin{array}{c}\text { Crossover } \\
\text { probability }\end{array}$ & $\begin{array}{c}\text { Mutation } \\
\text { probability }\end{array}$ \\
\hline 500 & 100 & 0.7 & 0.2 \\
\hline
\end{tabular}

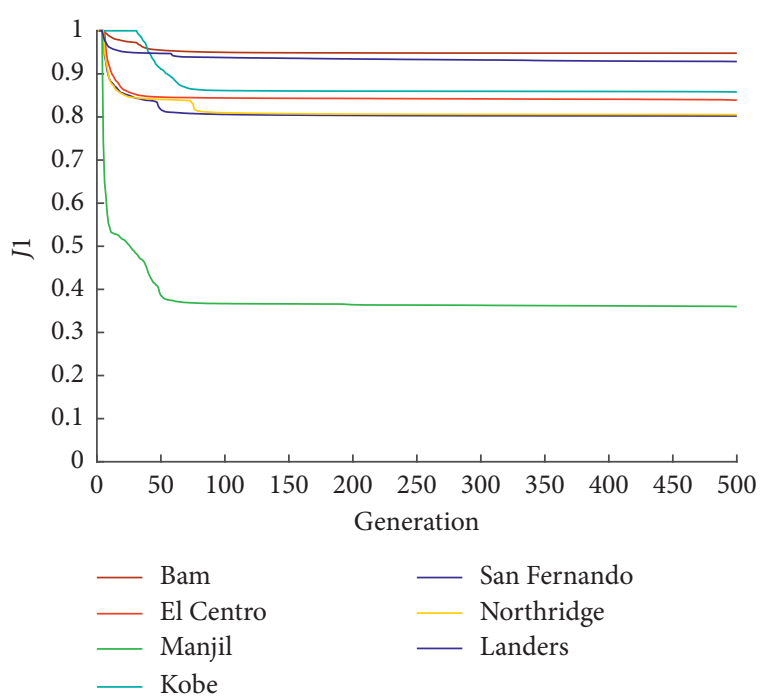

Figure 10: Trend of objectives during the generations.

and 64th floors in both cases. Under both sets of excitations, most of the mass for the TMDs was dedicated to those on the top two floors. The tuned frequency of the TMDs was close to the fundamental frequency of the building for the top two TMDs and about 1.24 times the fundamental frequency for the TMD in the 64th-floor building. The damping ratio of the TMDs placed on the top two stories was close to the maximum allowed value, which was 40 , while it was about 14 for the TMD in the 64th-floor building.

It was observed that the controlled displacement responses of the building improved substantially by about $65 \%$ under the Manjil earthquake excitation. On the contrary, the objective $J_{1}$ for the Bam earthquake had a value of about 0.95 , which means to about $5 \%$ improvement in reducing maximum displacements, compared to the uncontrolled response. This low objective value was also obtained under the Landers earthquake, with a value of about 0.93 for $J_{1}$, implying $7 \%$ improvement in reducing the displacement responses. However, the displacement response shows substantial improvements in damping further oscillations compared to uncontrolled buildings.

For Landers, Northridge, and San Fernando earthquakes, the TMDs were placed on stories 76 and 74, and most of the allowed mass was dedicated to the TMD on the roof. The optimum tuning frequency of the TMDs was close to the fundamental frequency of the building. The damping values of the TMDs were between 36.39 and 39.78, which were close to the maximum considered damping ratio.

For the El Centro and Kobe earthquakes, the optimum results were obtained by placing a single TMD system on the roof. In both cases, all the allowed mass was utilized in the TMD. Under these excitations, the frequency ratios of the TMDs were registered as 1.06 and 1.05 , which indicated a tuning frequency closer to the fundamental frequency of the building; the damping ratios of the TMDs were 39.53 and 39.78 , which were close to the maximum allowed value.

\section{Discussion}

As mentioned in Results, the optimum target stories for placing the TMDs included the top two stories for all of the earthquake excitations and some other stories such as 74 and 64 for some of the earthquakes. In order to understand the reasons behind this optimum arrangement, the building's mode shapes are again presented in Figure 18, but in each mode, the stories with maximum displacements are also marked. As shown, for the first three modes, the top three stories have the maximum displacements. The roof and the 75th and 61st stories, for the 4th mode, and the roof and the 75th and 64th stories, for the 5th mode, were the stories with maximum modal displacements.

Consequently, it can be concluded that placing a TMD on the top stories would improve the modal displacements in all five modes, an observation which agrees with the optimization results.

On the contrary, for some earthquakes, TMDs were placed in the lower stories, which implies that the optimum placement of the TMDs may also be related to some excitation parameters. For this reason, fast Fourier transformation (FFT) was performed for each earthquake's excitation record, and amplitudes for each building's mode frequency were then specified to investigate the effective properties of the excitations, as shown in Figure 19.

As shown here, unlike other earthquakes, for the Bam and Manjil earthquakes, the amplitude of the excitation in the 4th and 5th modes is more than that in the lower modes. As a result, although these higher modes have lower mass participation factors, their participation in the total response of the earthquake is increased by higher excitation amplitudes. In order to theoretically study these results, the displacement response of the building under the ground motion is presented in equation (9) as sum of the modal nodal displacements:

$$
\mathbf{u}(t)=\sum_{n=1}^{N} \mathbf{u}_{n}(t)
$$




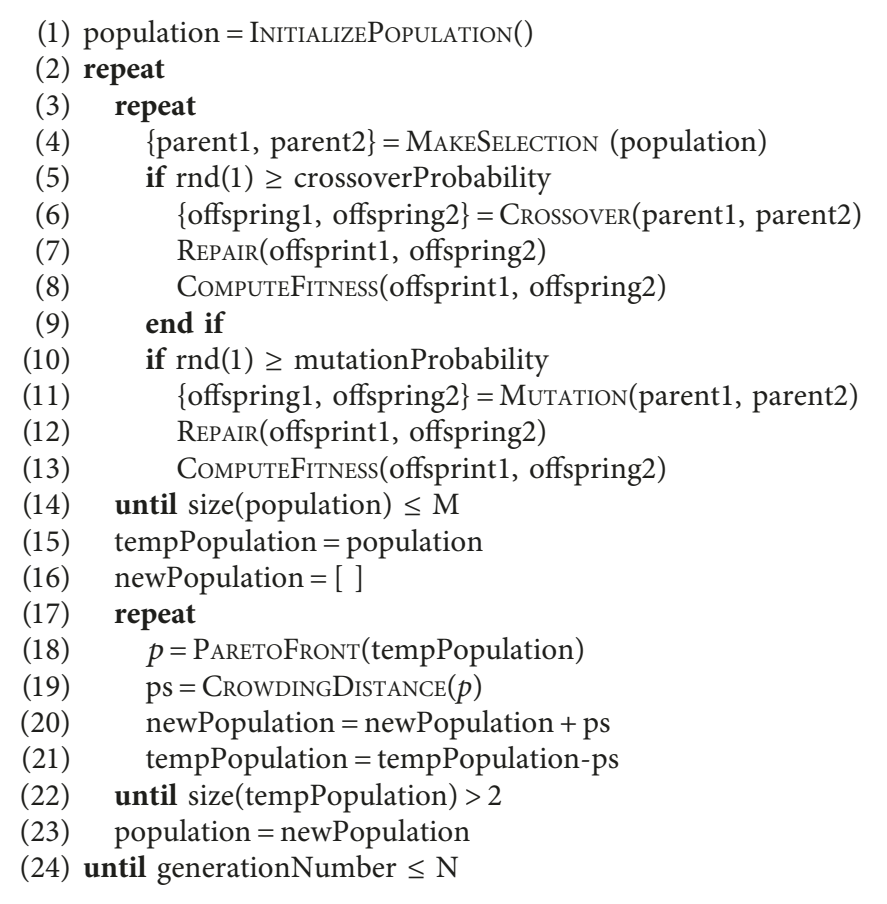

Algorithm 6: NSGA-II.

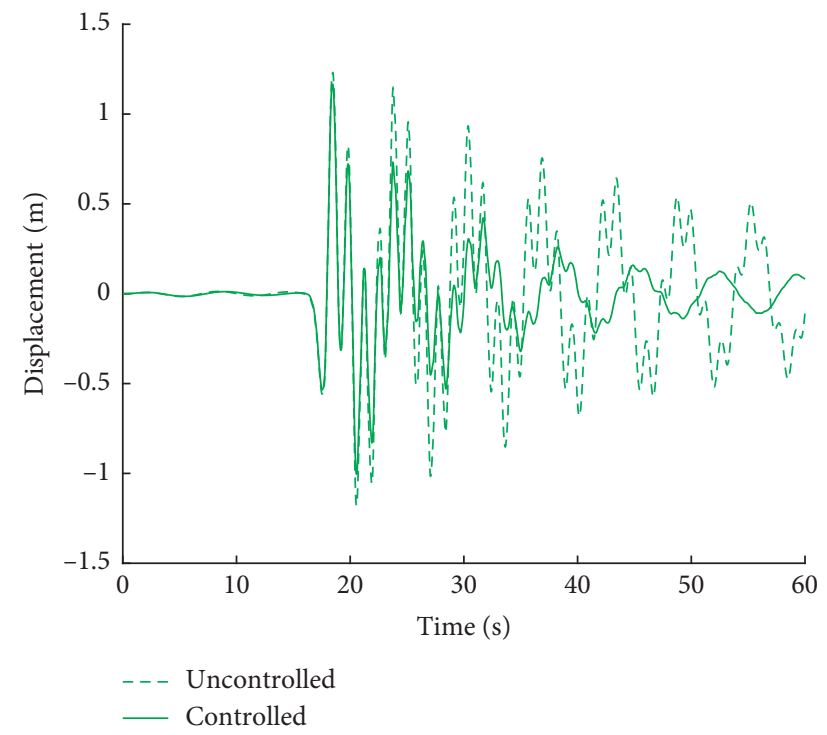

(a)

\begin{tabular}{|c|c|c|c|c|c|c|}
\hline Story & $m_{0}$ & $\beta$ & $\psi$ & & & \\
\hline 76 & 1.43 & 0.98 & 39.53 & & & \\
\hline 75 & 0.93 & 1.01 & 39.46 & $\overline{J_{1}}$ & $J_{2}$ & $J_{3}$ \\
\hline 64 & 0.64 & 1.24 & 18.37 & 0.95 & 0.88 & 0.83 \\
\hline
\end{tabular}

(b) (c)

Figure 11: Uncontrolled/controlled responses under the Bam earthquake. (a) Roof displacement response. (b) TMD specifications. (c) Objective values.

where $\mathbf{u}_{n}$ represents the $n$th mode's displacements. The contribution of the $n$th mode to the nodal displacement $\mathbf{u}(t)$ is

$$
\mathbf{u}_{n}(t)=\phi_{n} q_{n}(t)
$$

where $q_{n}$ refers to the modal coordinate which can be calculated from the following equation:

$$
\ddot{q}_{n}+2 \zeta_{n} \omega_{n} \dot{q}_{n}+\omega_{n}^{2} q_{n}=-\Gamma_{n} \ddot{u}_{g}(t),
$$

where $\Gamma_{n}$ is the modal participation factor of the $n$th mode and is the degree to which the $n$th mode participates in the total response. The modal participation factor can be calculated based on the modal displacements and masses as follows: 


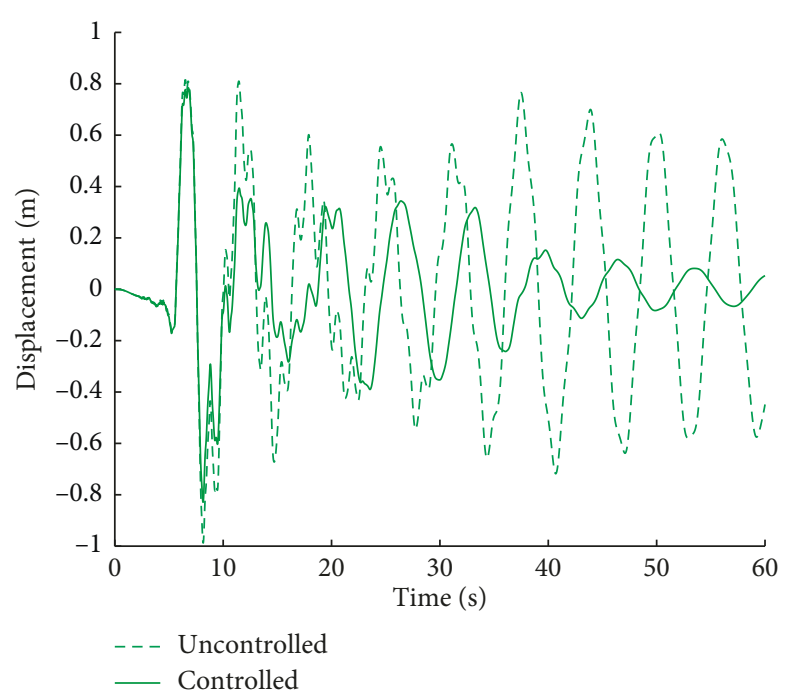

(a)

\begin{tabular}{lccc}
\hline Story & $m_{0}$ & $\beta$ & $\psi$ \\
\hline 76 & 2.99 & 1.06 & 39.53 \\
\hline
\end{tabular}

(b)

\begin{tabular}{lcc}
\hline$J_{1}$ & $J_{2}$ & $J_{3}$ \\
\hline 0.84 & 0.91 & 0.93 \\
\hline
\end{tabular}

(c)

FIGURE 12: Uncontrolled/controlled responses under the El Centro earthquake. (a) Roof displacement response. (b) TMD specifications. (c) Objective values.

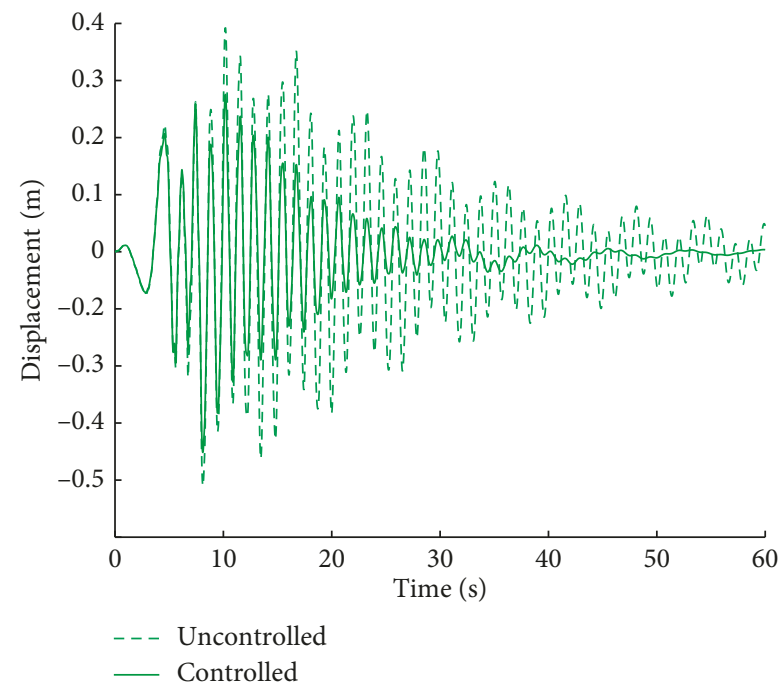

(a)

\begin{tabular}{lccc}
\hline Story & $m_{0}$ & $\beta$ & $\psi$ \\
\hline 76 & 3.00 & 1.05 & 39.78 \\
\hline
\end{tabular}

(b)

\begin{tabular}{ccc}
\hline$J_{1}$ & $J_{2}$ & $J_{3}$ \\
\hline 0.86 & 0.90 & 0.97 \\
\hline
\end{tabular}

(c)

FIgURE 13: Uncontrolled/controlled responses under the Kobe earthquake. (a) Roof displacement response. (b) TMD specifications. (c) Objective values.

$$
\Gamma_{N}=\frac{\left\{\phi_{n}\right\}[M]\{1\}}{\left\{\phi_{n}\right\}^{T}[M]\left\{\phi_{n}\right\}}=\frac{\sum_{j=1}^{N} m_{j} \phi_{j n}}{\sum_{j=1}^{N} m_{j}^{n} \phi_{j n}^{2}} .
$$

Equation (11) is related to a single-degree-of-freedom (SDOF) system with frequency and damping corresponding to the $n$th mode.

As shown here, in each mode $n$, the nodal displacement $\mathbf{u}_{n}(t)$ has a direct relationship with the modal displacements, $\phi_{n}$, which means that the stories with maximum modal displacements would have greater participation in the building's modal response. In addition, it is obvious that the modal response in the $n$th mode is also related to the frequency content of the earthquake excitation, $\ddot{u}_{\mathrm{g}}$, which means that a larger acceleration amplitude at that mode's frequency would result in larger modal responses for that mode.

Therefore, the participation of a particular story in the total response of the building would be more than that of the other stories if the following conditions are met:

(1) The story has maximum modal displacement in the modes with a larger modal participation factor

(2) The story has maximum modal displacement in the $n$th mode with a lower participation factor, but the ground motion has a larger Fourier transformation amplitude in the $n$th mode's frequency $\left(f_{n}\right)$ 


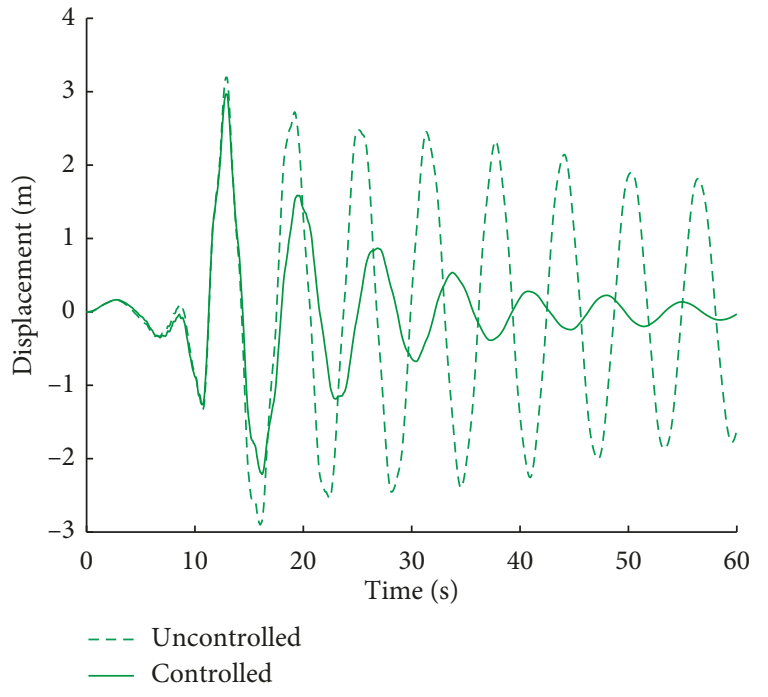

(a)

\begin{tabular}{lccc}
\hline Story & $m_{0}$ & $\beta$ & $\psi$ \\
\hline 76 & 2.01 & 1.01 & 37.07 \\
74 & 1.00 & 1.01 & 37.13 \\
\hline
\end{tabular}

(b)

\begin{tabular}{ccc}
\hline$J_{1}$ & $J_{2}$ & $J_{3}$ \\
\hline 0.93 & 0.89 & 0.98 \\
\hline
\end{tabular}

(c)

FIGURE 14: Uncontrolled/controlled responses under the Landers earthquake. (a) Roof displacement response. (b) TMD specifications. (c) Objective values.

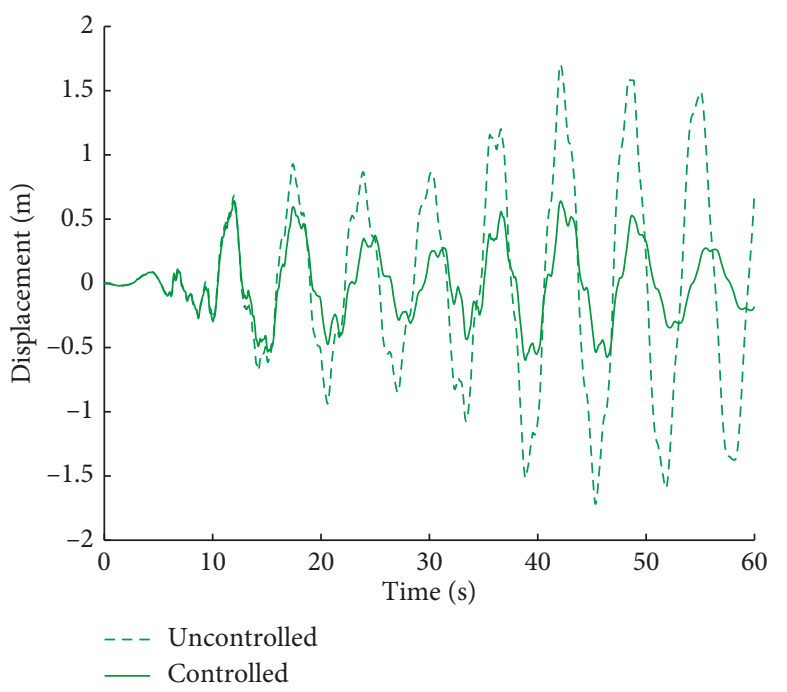

(a)

\begin{tabular}{lccc}
\hline Story & $m_{0}$ & $\beta$ & $\psi$ \\
\hline 76 & 1.50 & 1.02 & 35.12 \\
75 & 0.95 & 1.01 & 31.34 \\
64 & 0.55 & 1.21 & 14.92 \\
\hline
\end{tabular}

(b)

\begin{tabular}{ccc}
\hline$J_{1}$ & $J_{2}$ & $J_{3}$ \\
\hline 0.36 & 0.57 & 0.95 \\
\hline
\end{tabular}

(c)

Figure 15: Uncontrolled/controlled responses under the Manjil earthquake. (a) Roof displacement response. (b) TMD specifications. (c) Objective values.

These derivations validate the possibility of placing the TMDs in stories other than the top stories, a conclusion that agrees with the optimization results.

\section{Conclusion}

Considering the obtained results and related discussions in previous sections, the following conclusions can be drawn:

(1) Compared to a single TMD on the roof level, a distributed MTMD system is more efficient in improving structural responses with the same amount of masses under excitation for earthquakes that have noticeable amplitude at the structure's frequencies at higher modes, a scenario likely to happen within the lifetime of a tall building.

(2) The optimum stories for placement of the TMDs includes

(a) The stories with maximum modal displacements in the lower structural modes

(b) The stories with maximum modal displacements in modes with frequencies at which the earthquake excitation has noticeable amplitudes 


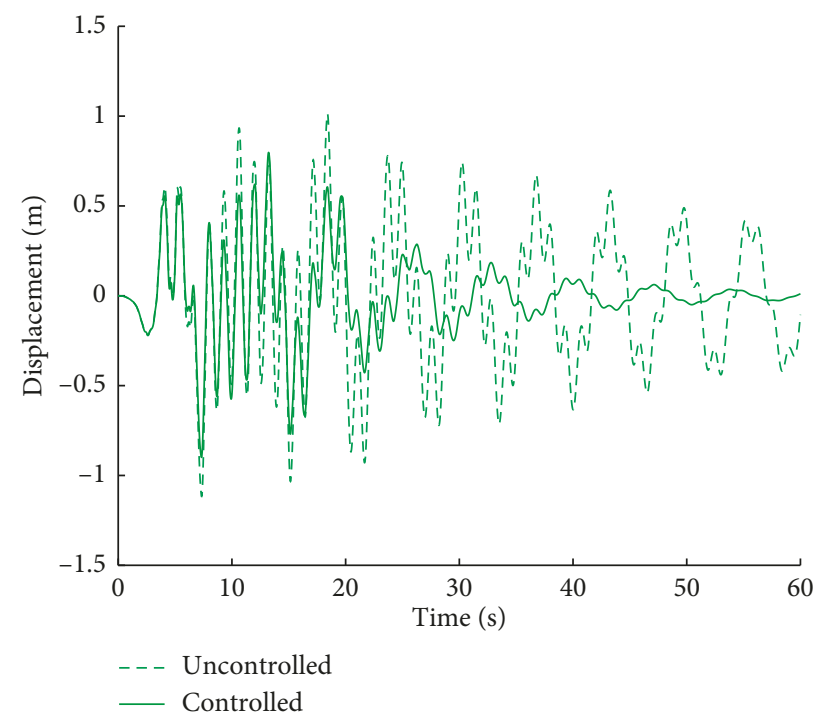

(a)

\begin{tabular}{lccc}
\hline Story & $m_{0}$ & $\beta$ & $\psi$ \\
\hline 76 & 2.26 & 1.04 & 37.05 \\
74 & 0.75 & 1.04 & 36.98 \\
\hline
\end{tabular}

\begin{tabular}{lcc}
\hline$J_{1}$ & $J_{2}$ & $J_{3}$ \\
\hline 0.81 & 0.84 & 0.95 \\
\hline
\end{tabular}

(b) (c)

FIGURE 16: Uncontrolled/controlled responses under the Northridge earthquake. (a) Roof displacement response. (b) TMD specifications. (c) Objective values.

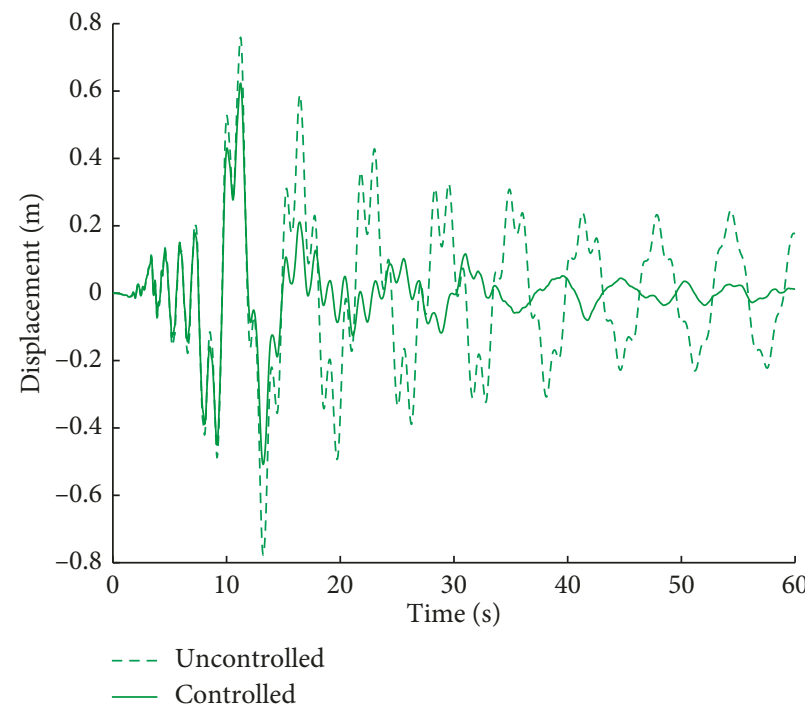

(a)

\begin{tabular}{lccc}
\hline Story & $m_{0}$ & $\beta$ & $\psi$ \\
\hline 76 & 2.28 & 1.03 & 36.27 \\
74 & 0.72 & 1.03 & 36.39 \\
\hline
\end{tabular}

(b)

\begin{tabular}{lcc}
\hline$J_{1}$ & $J_{2}$ & $J_{3}$ \\
\hline 0.80 & 0.84 & 0.97 \\
\hline
\end{tabular}

(c)

Figure 17: Uncontrolled/controlled responses under the San Fernando earthquake. (a) Roof displacement response. (b) TMD specifications. (c) Objective values.

TABLE 8: Comparison between controlled and uncontrolled drifts and absolute accelerations of the top story for different earthquake excitations.

\begin{tabular}{lcccc}
\hline Earthquake & Max. drift (uncontrolled) & Max. drift (controlled) & $\begin{array}{c}\text { Max. absolute acceleration } \\
\left.\text { (uncontrolled, } \mathrm{m} / \mathrm{s}^{2}\right)\end{array}$ & $\begin{array}{c}\text { Max. absolute acceleration } \\
\left(\text { controlled, } \mathrm{m} / \mathrm{s}^{2}\right)\end{array}$ \\
\hline Bam & 0.0184 & 0.0172 & 34.94 & 17.32 \\
El Centro & 0.0128 & 0.0111 & 20.99 & 16.11 \\
Kobe & 0.0079 & 0.0066 & 25.72 & 21.40 \\
Manjil & 0.0159 & 0.0074 & 28.51 & 9.30 \\
Northridge & 0.0178 & 0.0146 & 23.87 & 15.55 \\
Landers & 0.0282 & 0.0262 & 28.94 & 14.79 \\
San Fernando & 0.0092 & 0.0075 & 21.61 & 12.35 \\
\hline
\end{tabular}



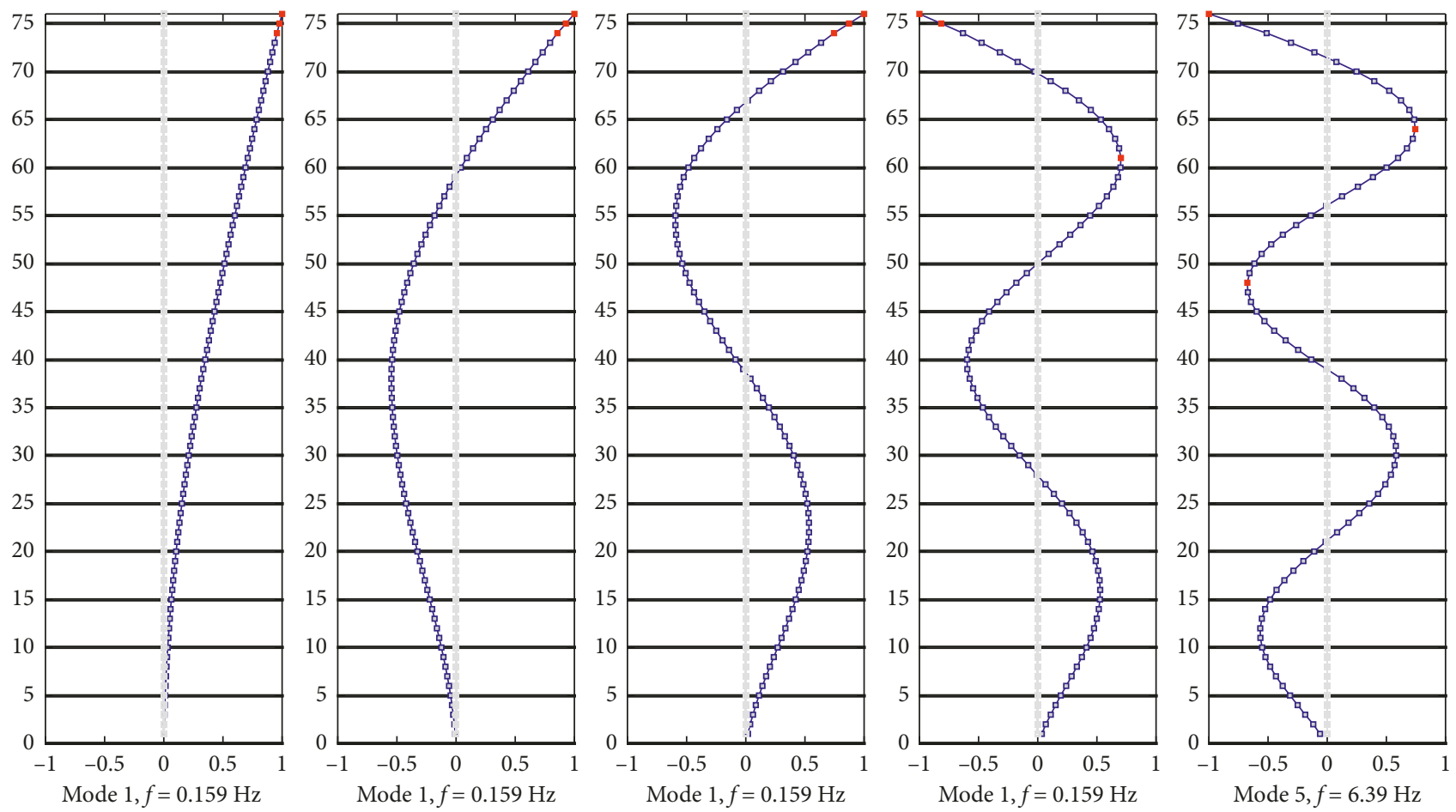

FIgURE 18: Three stories with maximum modal displacements in the first five natural modes.

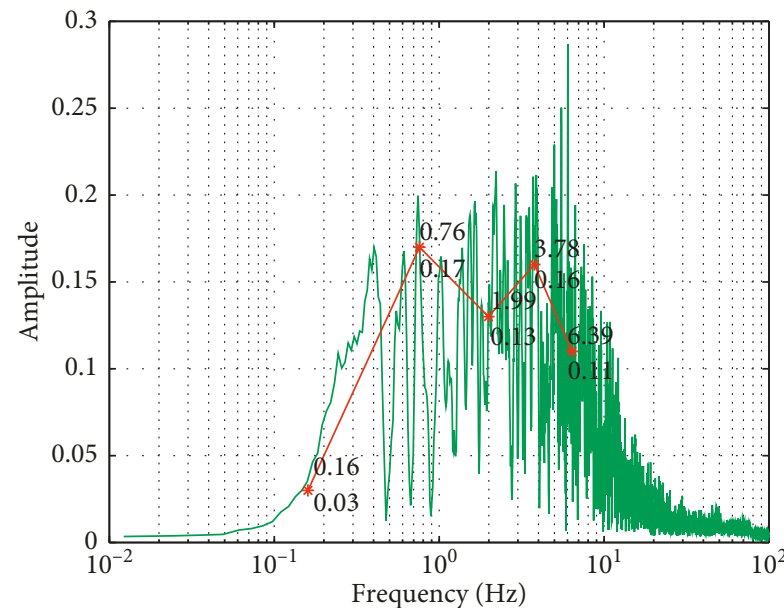

(a)

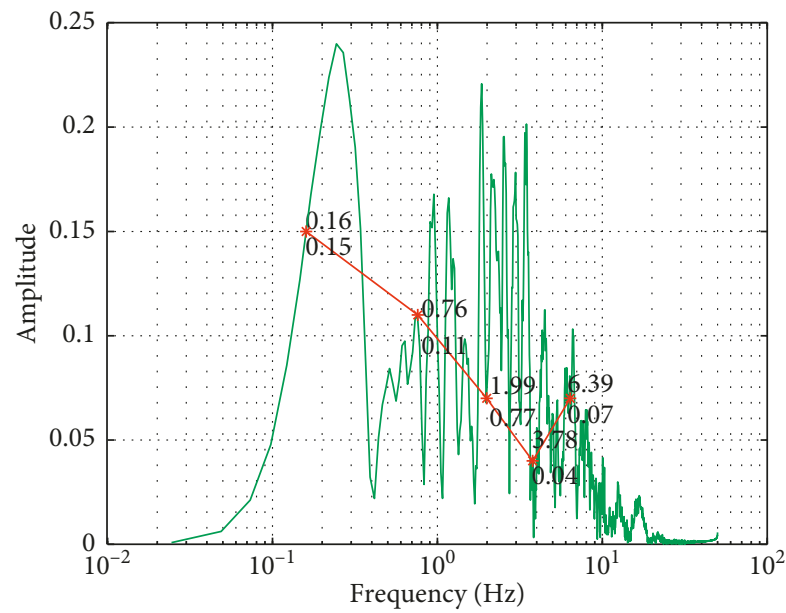

(c)

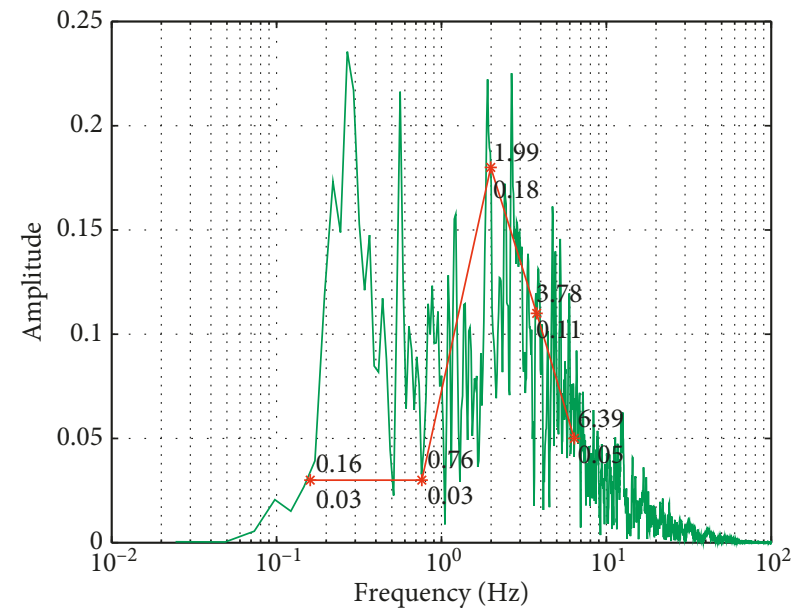

(b)

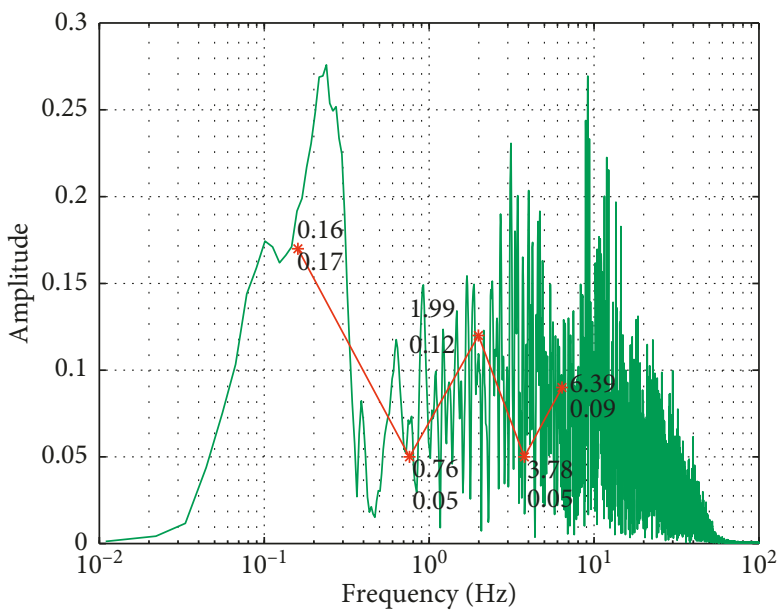

(d)

Figure 19: Continued. 


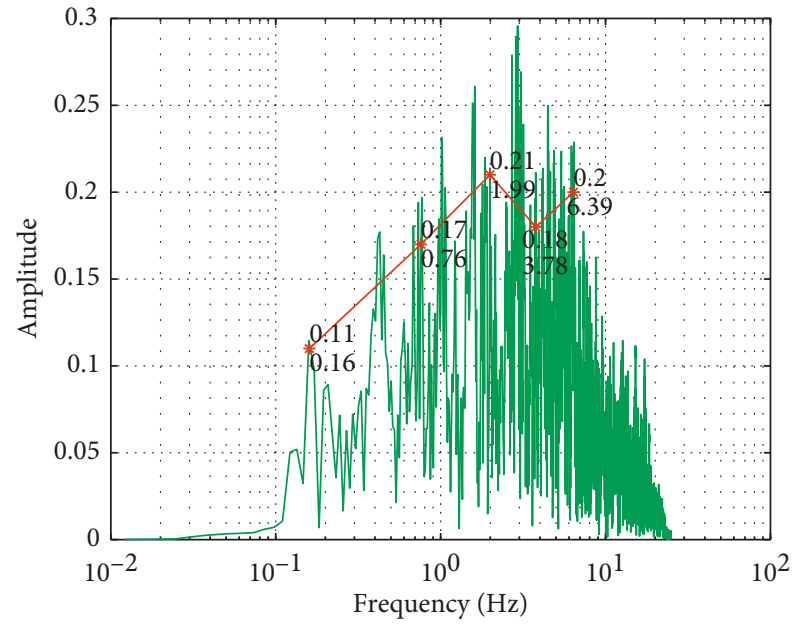

(e)

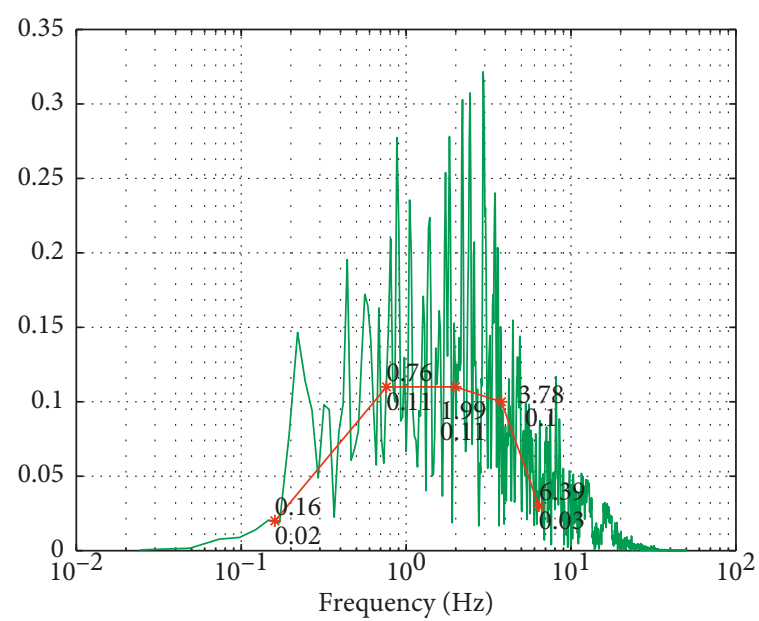

(f)

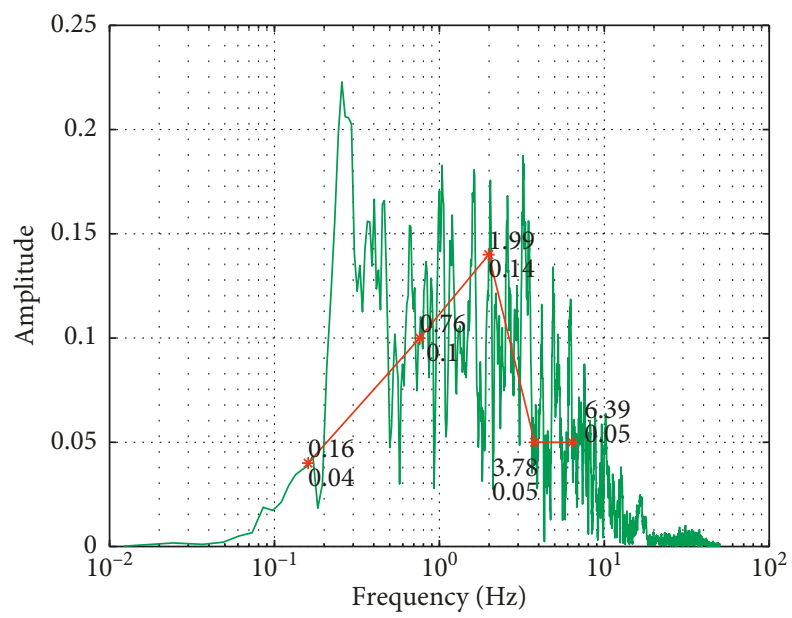

(g)

Figure 19: Fourier transform of earthquake excitations. (a) Bam. (b) El Centro. (c) Kobe. (d) Landers. (e) Manjil. (f) Northridge. (g) San Fernando.

(3) The optimum parameters for the TMDs that control the vibrations in the lower modes include the maximum allowed damping ratio. This indicates that increasing the damping ratio would improve the performance of such TMDs.

(4) The results showed that the performance of the TMDs was not good in reducing the initial maximums in displacement responses compared to their reduction of the later maximums that occurred after some initial oscillations.

(5) Even in the cases with immediate maximum displacement responses, the MTMD system significantly improves the damping.

\section{Data Availability}

The data used to support the findings of this study are available from the corresponding author upon request.

\section{Conflicts of Interest}

The authors declare that they have no conflicts of interest.

\section{References}

[1] M. M. Ali and K. S. Moon, "Structural developments in tall buildings: current trends and future prospects," Architectural Science Review, vol. 50, no. 3, pp. 205-223, 2007.

[2] B. F. Spencer and M. K. Sain, "Controlling buildings: a new frontier in feedback," IEEE Control Systems Magazine, vol. 17, no. 6, pp. 19-35, 1997.

[3] T. T. Soong and B. F. Spencer, "Supplemental energy dissipation: state-of-the-art and state-of-the-practice," Engineering Structures, vol. 24, no. 3, pp. 243-259, 2002.

[4] S. J. Moon, L. A. Bergman, and P. G. Voulgaris, "Sliding mode control of cable-stayed bridge subjected to seismic excitation," Journal of Engineering Mechanics, vol. 129, no. 1, pp. 71-78, 2003.

[5] J. F. Wang, C. C. Lin, and B. L. Chen, "Vibration suppression for high-speed railway bridges using tuned mass dampers," International Journal of Solids and Structures, vol. 40, no. 2, pp. 465-491, 2003.

[6] Y. Arfiadi and M. N. S. Hadi, "Optimum placement and properties of tuned mass dampers using hybrid genetic algorithms," International Journal of Optimization in Civil Engineering, vol. 1, no. 1, pp. 167-187, 2011. 
[7] A. Y. T. Leung and H. Zhang, "Particle swarm optimization of tuned mass dampers," Engineering Structures, vol. 31, no. 3, pp. 715-728, 2009.

[8] G. Chen and J. Wu, "Optimal placement of multiple tune mass dampers for seismic structures," Journal of Structural Engineering, vol. 127, no. 9, pp. 1054-1062, 2001.

[9] S. Elias and V. Matsagar, "Distributed multiple tuned mass dampers for wind vibration response control of high-rise building," Journal of Engineering, vol. 2014, Article ID 198719, 11 pages, 2014.

[10] C.-L. Lee, Y.-T. Chen, L.-L. Chung, and Y.-P. Wang, "Optimal design theories and applications of tuned mass dampers," Engineering Structures, vol. 28, no. 1, pp. 43-53, 2006.

[11] C. Li and B. Zhu, "Estimating double tuned mass dampers for structures under ground acceleration using a novel optimum criterion," Journal of Sound and Vibration, vol. 298, no. 1-2, pp. 280-297, 2006.

[12] R. N. Jabary and S. P. G. Madabhushi, "Tuned mass damper effects on the response of multi-storied structures observed in geotechnical centrifuge tests," Soil Dynamics and Earthquake Engineering, vol. 77, pp. 373-380, 2015.

[13] H.-C. Tsai and G.-C. Lin, "Optimum tuned-mass dampers for minimizing steady-state response of support-excited and damped systems," Earthquake Engineering \& Structural Dynamics, vol. 22, no. 11, pp. 957-973, 1993.

[14] Y. L. Xu, J. Chen, C. L. Ng, and W. L. Qu, "Semiactive seismic response control of buildings with podium structure," Journal of Structural Engineering, vol. 131, no. 6, pp. 890-899, 2005.

[15] T. A. Sakr, "Vibration control of buildings by using partial floor loads as multiple tuned mass dampers," HBRC Journal, vol. 13, no. 2, pp. 133-144, 2017.

[16] L. Zuo and S. A. Nayfeh, "Optimization of the individual stiffness and damping parameters in multiple-tuned-massdamper systems," Journal of Vibration and Acoustics, vol. 127, no. 1, p. 77, 2005.

[17] N. Hoang and P. Warnitchai, "Design of multiple tuned mass dampers by using a numerical optimizer," Earthquake Engineering \& Structural Dynamics, vol. 34, no. 2, pp. 125-144, 2005.

[18] M. Jokic, M. Stegic, and M. Butkovic, "Reduced-order multiple tuned mass damper optimization: a bounded real lemma for descriptor systems approach," Journal of Sound and Vibration, vol. 330, no. 22, pp. 5259-5268, 2011.

[19] A. Y. Pisal and R. S. Jangid, "Seismic response of multi-story structure with multiple tuned mass friction dampers," International Journal of Advanced Structural Engineering, vol. 6, no. 1, pp. 1-13, 2014.

[20] C. Li and W. Qu, "Optimum properties of multiple tuned mass dampers for reduction of translational and torsional response of structures subject to ground acceleration," Engineering Structures, vol. 28, no. 4, pp. 472-494, 2006.

[21] "Tallest 10 completed buildings with dampers," CTBUH Journal, vol. 48, no. 3, 2018, https://www.google.com/url? $\mathrm{sa}=\mathrm{t} \& \mathrm{rct}=\mathrm{j} \& \mathrm{q}=\& \mathrm{esrc}=\mathrm{s} \&$ source $=$ web $\& \mathrm{~cd}=1 \& \mathrm{cad}=\mathrm{rja} \& u a c t=$ 8\&ved=2ahUKEwiZv-L82JvkAhXKI1AKHbMDBIwQFjAAeg QIABAC\&url=http\%3A\%2F\%2Fglobal.ctbuh.org\%2Fpaper\% 2F3788\&usg=AOvVaw2F_KHUsmgWNYnY_pgGXE1f.

[22] C. C. Chang and W. L. Qu, "Unified dynamic absorber design formulas for wind-induced vibration control of tall buildings," The Structural Design of Tall Buildings, vol. 7, no. 2, pp. 147-166, 1998.

[23] S. N. Deshmukh and N. K. Chandiramani, "LQR control of wind excited benchmark building using variable stiffness tuned mass damper," Shock and Vibration, vol. 2014, Article ID 156523, 12 pages, 2014.

[24] S. Pourzeynali, S. Salimi, and H. E. Kalesar, "Robust multiobjective optimization design of TMD control device to reduce tall building responses against earthquake excitations using genetic algorithms," Scientia Iranica, vol. 20, no. 2, pp. 207-221, 2013.

[25] S. Elias, V. Matsagar, and T. K. Datta, "Effectiveness of distributed tuned mass dampers for multi-mode control of chimney under earthquakes," Engineering Structures, vol. 124, pp. 1-16, 2016.

[26] S. Elias and V. Matsagar, "Research developments in vibration control of structures using passive tuned mass dampers," Annual Reviews in Control, vol. 44, pp. 129-156, 2017.

[27] N. M. Newmark, "A method of computation for structural dynamics," Journal of the Engineering Mechanics Division, vol. 85, no. 3, pp. 67-94, 1959.

[28] K. Deb, A. Pratap, S. Agarwal, and T. Meyarivan, “A fast and elitist multiobjective genetic algorithm: NSGA-II," IEEE Transactions on Evolutionary Computation, vol. 6, no. 2, pp. 182-197, 2002.

[29] O. Kramer, Genetic Algorithm Essentials, Springer Publishing Company, New York, NY, USA, 1st edition, 2017.

[30] D. E. Goldberg and K. Deb, "A comparative analysis of selection schemes used in genetic algorithms," Foundations of Genetic Algorithms, vol. 1, pp. 69-93, 1991.

[31] PEER Center, PEER Ground Motion Database, PEER Center, University of California, Berkeley, CA, USA, https://ngawest2. berkeley.edu/.

[32] I. Iervolino, C. Galasso, and E. Cosenza, "REXEL: computer aided record selection for code-based seismic structural analysis," Bulletin of Earthquake Engineering, vol. 8, no. 2, pp. 339-362, 2010.

[33] F. Weber, J. Distl, L. Meier, and C. Braun, "Curved surface sliders with friction damping, linear viscous damping, bow tie friction damping, and semiactively controlled properties," Structural Control and Health Monitoring, vol. 25, no. 11, p. e2257, 2018.

[34] M. Gen and R. Cheng, Genetic Algorithms and Engineering Optimization, John Wiley \& Sons, Hoboken, NJ, USA, 2000. 


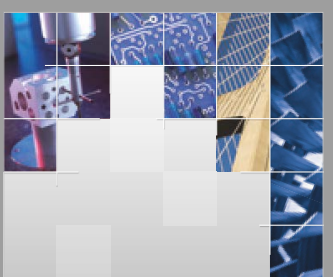

\section{Enfincering}
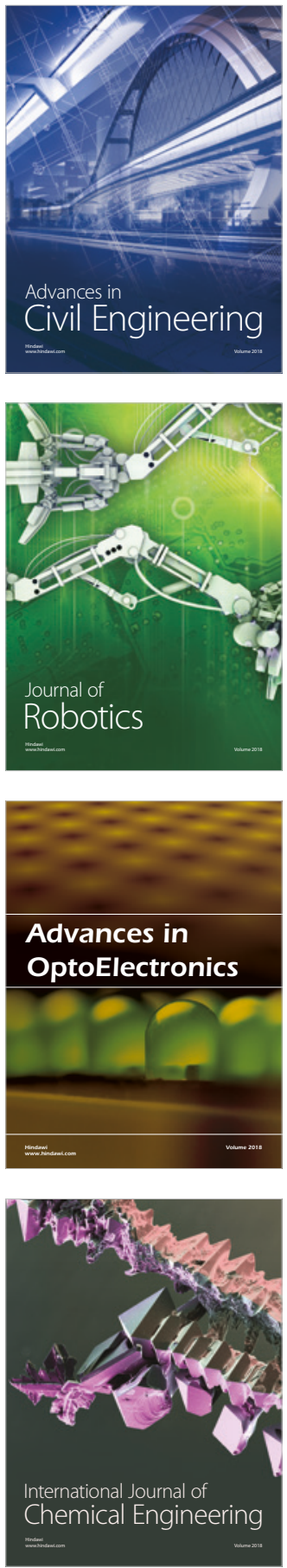

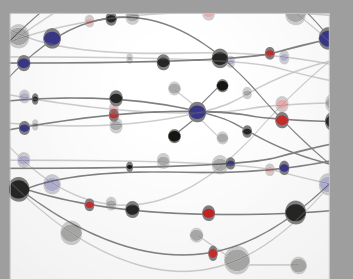

\section{Rotating \\ Machinery}

The Scientific World Journal

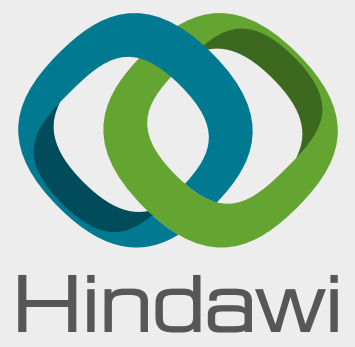

Submit your manuscripts at

www.hindawi.com
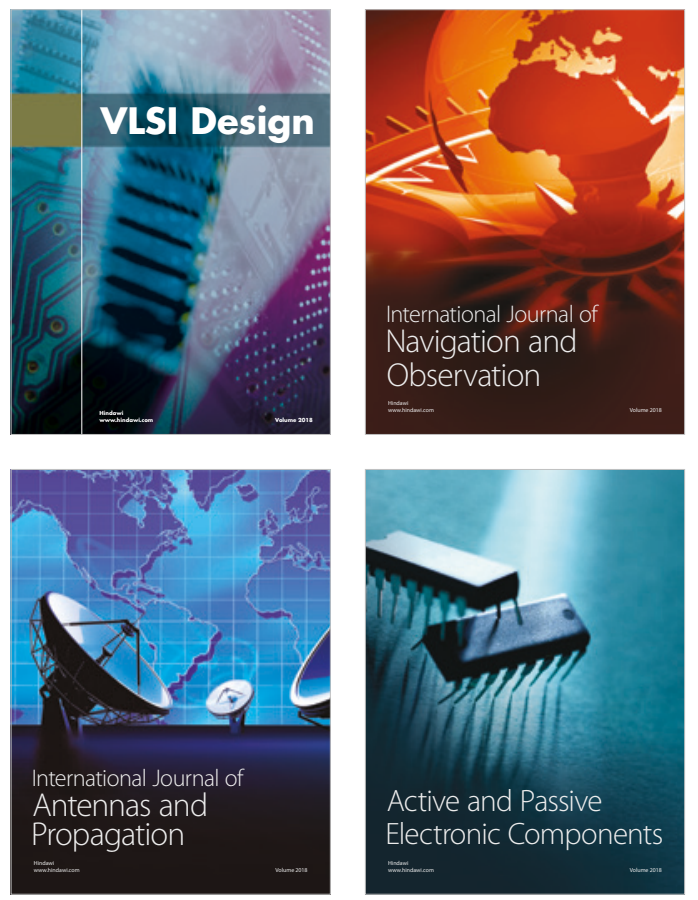
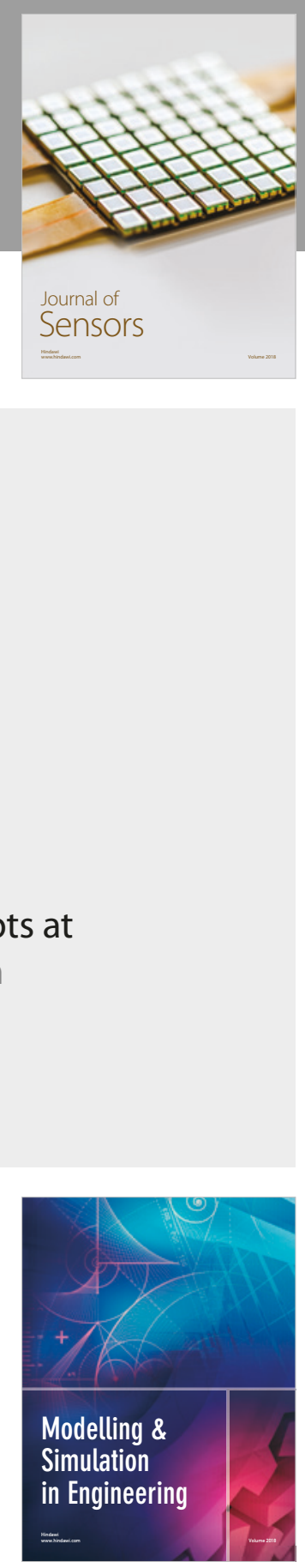

\section{Advances \\ Multimedia}
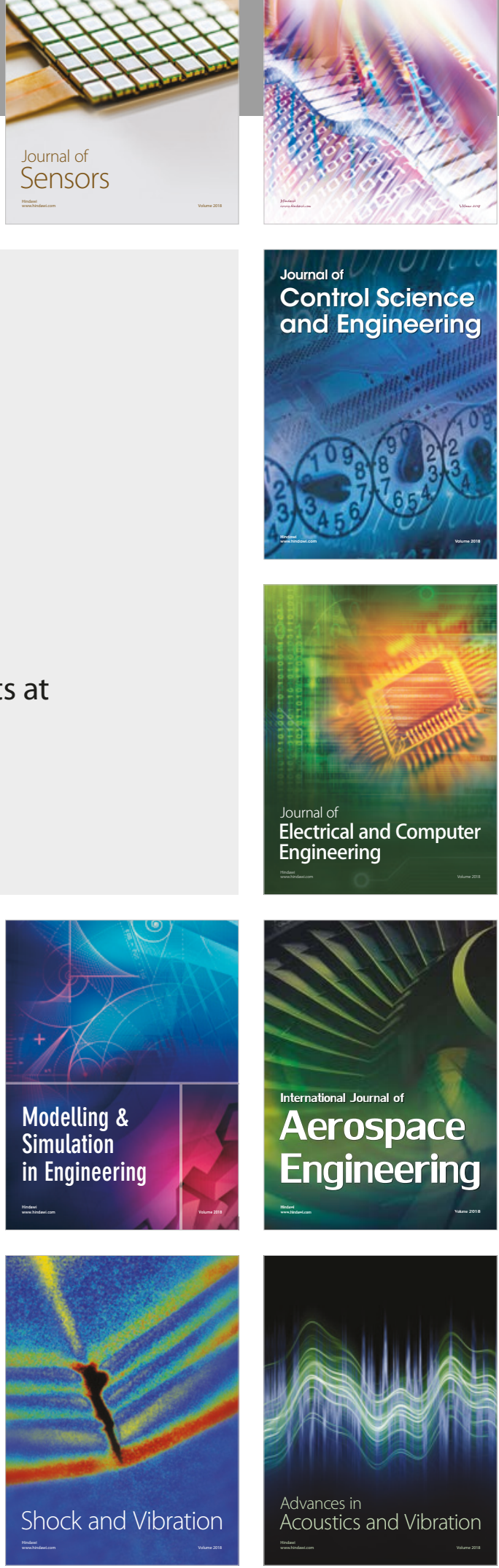